\title{
Conflicto mapuche-campesino en la Araucanía: un análisis a partir de la Estructura de Oportunidades Políticas (EOP). 1967-1973*
}

\author{
Mapuche-farmer conflict in the Araucanía: an analysis by the \\ Political Opportunity Structures (POS). 1967-1973
}

\begin{abstract}
Mathias Órdenes Delgado**
Resumen: En este artículo explicamos las condiciones sociopolíticas que favorecieron la alianza entre el movimiento mapuche y el campesino, y el consecuente estallido del movimiento social mapuche-campesino en la Araucanía durante la Reforma Agraria. En segundo lugar, también explicamos el desarrollo de los sectores y tipos de movilización que dividieron al movimiento. Sostenemos que a partir de 1958 hasta el golpe de Estado, existieron condiciones objetivas que catalizaron el conflicto mapuche-campesino, permitiendo a los sujetos implementar nuevas estrategias de movilización. Estas condiciones se estructuraron a partir de la ampliación democrática que surgió con la dictación de la Ley de Reforma Electoral y del corpus legal que profundizó la Reforma Agraria en 1967, en el gobierno de Frei Montalva y luego en el de Allende, a lo que se sumaría el apoyo brindado al movimiento por la izquierda revolucionaria y los partidos. Ello permitió la conformación de lo que se conoce como una Estructura de Oportunidades Políticas favorable al movimiento mapuchecampesino, el cual se dividió en dos grandes sectores, que reflejaron las alternativas posibles de movilización: dentro de la institucionalidad y fuera de ella.
\end{abstract}

Palabras clave: Movimiento mapuche-campesino, Conflicto social, Estructura de Oportunidades Políticas, Reforma Agraria.

Abstract: In this article we explain the sociopolitical conditions that favored the
alliance between the Mapuche and the farmer movement, and the resulting outbreak of
the Mapuche-farmer social movement in the Araucanía during the agrarian reform.
Secondly, we also explain the development of the sectors and types of mobilization
that divided the movement. We argue that from 1958 until the coup d'état, there were
objective conditions that catalyzed the Mapuche-farmer conflict, allowing to the
subjects to implement new strategies of mobilization. These conditions were
structured from the democratic expansion that came with the enactment of the
Electoral Reform Law and the legal corpus that deepened the Agrarian Reform in

* El presente artículo comprende investigaciones realizadas en el marco de la tesis doctoral del autor, "Movimiento mapuche y gobernabilidad democrática. De la Reforma Agraria al Gobierno de Sebastián Piñera (1967-2014)", para el Doctorado en Procesos Sociales y Políticos en América Latina, Universidad ARCIS, 2014. La investigación financiada enteramente por el autor.

** Investigador del Instituto de Estudios Indígenas, Universidad de la Frontera, Profesor de Estado en Historia, Geografía y Educación Cívica, Máster en Ciencias Sociales, Doctor en Procesos Sociales y Políticos en América Latina. E-mal: mathias.ordenes@gmail.com 
1967, in the Frei Montalva and then in the Allende government, to which the support of the movement would be added by the revolutionary left and the parties. These conditions allowed the creation of what is known as a Political Opportunity Structure favourable to the Mapuche-farmer movement, which was divided into two major sectors, that reflected the possible mobilization alternatives: within the institution and out of this.

Keywords: Mapuche-farmer movement, social conflict, Political Opportunity Structures and Agrarian Reform.

\section{Introducción}

Con la implementación de la Reforma Agraria (1962-1973) se produjo un fenómeno muy interesante: el movimiento mapuche se reconfigura y, en alianza con los campesinos pobres no mapuche, logra constituir en la Araucanía un gran movimiento campesino e indígena, el único de su tipo en toda la historia patria. Aunque, como veremos, ambos sectores tenían su propia historia y demandas distintas, los unió un objetivo mayor: reclamar las tierras del latifundio para terminar con la repartición desigual de propiedad privada rural y con las injusticias históricas que los afectaban. Dicha movilización social se encontró dividida en dos grandes sectores ideológicos y programáticos: uno comprometido con el surgimiento de un nuevo tipo de izquierda, nacida en el marco del escenario generado a partir de la Revolución Cubana. Esta fue una izquierda más insurrecta y subversiva, lejana a la política partidista tradicional. Y un segundo sector, menos subversivo, formado al alero de los nacientes sindicatos campesino y de los partidos políticos tradicionales de centro e izquierda. Esto se tradujo, con notoriedad a partir de 1967, en que el primer sector del movimiento inicia un proceso intenso de "recuperaciones", "ocupaciones" y "tomas" de fundos en la Araucanía y otras zonas al sur del Biobío; en tanto que el segundo, organiza distintas vías de negociación con las autoridades.

Entre los resultados más visibles de la alianza mapuche-campesina, fue el hecho de que a partir de la convergencia entre el Movimiento de Izquierda Revolucionaria (MIR) y un grupo de comunidades mapuche nacerá en la provincia de Cautín, en 1968, el Movimiento Campesino Revolucionario (MCR). Esta sería la más notoria de las organizaciones mapuche-campesinas que plantearon la vía insurreccional para la desintegración del latifundio, etapa que fue considerada clave para la implementación de un régimen socialista de tenencia de la tierra (Carvajal y Peralta 2006; Alfaro 2011). Alrededor de ese año también nacen organizaciones similares $y$, al igual que en la anterior, participaron mapuche y no mapuche, como la Cooperativa Lautaro de Lumaco, la Confederación Campesina e Indígena Ranquil, la Unión Campesina Revolucionaria y el Movimiento Netuaiñ Mapu. Con el surgimiento de estas organizaciones se constata con claridad la colaboración del movimiento revolucionario con los sectores más reaccionarios del movimiento mapuche. A estas organizaciones se sumaban otras menos revolucionarias, como la Federación 
Campesina e Indígena, la Confederación Nacional Mapuche, la Unión de Mapuches de Chile y la Confederación Nacional Campesina e Indígena de la Provincia de Malleco, todas fuertemente vinculadas a los partidos políticos tradicionales (Foerster y Montecinos 1988: 285-358; Bengoa 2002: 17-23).

Como es sabido, este proceso se desarrolló en medio de un escenario sociopolítico muy complejo. Por un lado, la Reforma Agraria que, como revisaremos, gracias a la ampliación del Estado benefactor entra en una etapa de profundización en el gobierno de Eduardo Frei Montalva, con su programa de Revolución en Libertad (1964-1970), y en gobierno de la Unidad Popular (UP) con Salvador Allende (1970-1973). Por otro lado, en plena Guerra Fría y tras la Revolución Cubana surge la llamada Nueva Izquierda Latinoamericana, planteando la vía insurreccional como medio para alcanzar la construcción del socialismo. Junto a ella y a otros movimientos del más variado corte ideológico (surgidos generalmente al alero de los partidos políticos), la organización obrera y campesina en general, e incluso barrial, se amplían y diversifican considerablemente hasta formar un gran movimiento social, que logró ser clave en el desarrollo de las políticas económicas y sociales del Estado benefactor, en la vida social y ciudadana y en los golpes de Estado que tristemente afectaron al Cono Sur, trayendo gran represión sobre el movimiento social.

Los autores que han trabajado el tema se han detenido profusamente en el análisis del complejo escenario de aquellos años, en especial, la Reforma Agraria, considerada clave para explicar el gran estallido que adquiere el movimiento campesino y el mapuchecampesino en la Araucanía (Bengoa 1985; Foerster y Montecinos 1988; Bengoa 2002; Mallon 2004; Toledo 2006; Correa, Molina y Yáñez 2005; Correa y Mella 2009) ${ }^{1}$. Sin embargo, se ha ido más allá, separando al movimiento mapuche del campesino para poner especial atención a lo que podríamos denominar como el análisis del movimiento mapuche "por dentro".

En lo concreto, se ha sostenido que las movilizaciones respondían a necesidades económicas concretas y a la exclusión histórica de los mapuche, junto a su fuerte conciencia sobre una larga historia de abusos por parte de terratenientes y el Estado, a lo se sumaba el aprendizaje político adquirido a partir de una dilatada trayectoria organizacional (la cual no es posible constatar con tanta claridad entre los campesinos pobres no mapuche $)^{2}$.

En esa misma línea se han estudiado las organizaciones y líderes del movimiento del siglo XX hasta el golpe de Estado, y se ha indicado que el debilitamiento de la Corporación Araucana a comienzos de los años 60 (principal organización del movimiento en la década del 50), habría contribuido fuertemente a la disgregación del movimiento y su pronta inclinación hacia el centro político y los movimientos de izquierda, debido principalmente a la incapacidad de la Corporación para renovar su proyecto político, pues en décadas

\footnotetext{
${ }^{1}$ Una mirada distinta al fenómeno nos entrega Heidi Tinsman (2009), utilizando el enfoque de género.

${ }^{2} \mathrm{Al}$ respecto y si se quiere revisar a los investigadores mapuche, ver algunos dos textos que se han vuelto bibliografía fundamental: Martín Correa y Eduardo Mella (2009), El territorio mapuche de Malleco: Las razones del illkun/enojo. Memoria, despojo y criminalización en el territorio mapuche de Malleco; Martín Correa; Raúl Molina y Nancy Yáñez (2005), La Reforma Agraria y las tierras mapuches. Chile 1962-1975.
} 
anteriores había apoyado a los candidatos conservadores (Foerster y Montecinos 1988: $256)^{3}$.

Desde la antropología histórica se ha argumentado que un factor muy significativo de movilización habría sido el "nativismo". Desde este punto de vista, "las tomas de fundos fueron un intento de los indígenas de recomponer la comunidad destruida en la ocupación de la Araucanía setenta años antes" (Bengoa 2002: 149-158).

Últimamente se ha puesto atención sobre el hecho de que al interior de las comunidades y organizaciones mapuche se vivió un intenso y democrático debate sobre las características que debía asumir el movimiento. En este debate habrían participado, también junto a mapuche, grupos de estudiantes universitarios, líderes del movimiento campesino e intelectuales vinculados al MIR y otros movimientos revolucionarios, cuestión que queda bastante confirmada por las historias testimoniales. En ese contexto, la revisión y acumulación de las historias de vida (la memoria oral del pueblo mapuche), habrían sido utilizadas, en medio de una coyuntura histórica clave, como un mecanismo de reclutamiento social y agenciamiento político que permitiría definir programas, trazar líneas de acción y aumentar el contingente de mapuche movilizados (Bengoa 2002; Caniuqueo 2006: 135-136; Carvajal y Peralta 2006) ${ }^{4}$. No deja de ser significativo que más recientemente, constataciones y análisis muy similares se han utilizado para ayudar a explicar el movimiento mapuche de fines de la dictadura hasta la actualidad (Tricot 2013; Levil 2006; Pairacan 2012). No podemos descartar la mayoría de los esfuerzos teóricos y recopilaciones empíricas de los autores mencionados, es más, en estas páginas recurrimos a ellos cuando consideramos necesario.

Sin embargo, constatamos que aunque los autores referidos al tema reconocen reiteradamente los lazos y vínculos organizacionales entre el movimiento mapuche y el movimiento campesino durante el período de la Reforma Agraria en la Araucanía, no han realizado esfuerzos por analizar el conflicto poniendo mayor atención en las características de la alianza que surge entre ambos movimientos, ni en las condiciones coyunturales y

\footnotetext{
${ }^{3}$ Quienes siguen esa lectura sobre la Corporación, particularmente respecto a su presidente Venancio Coñoepan, han obstaculizado un conocimiento más amplio sobre el movimiento mapuche "de derecha", al tildarlo únicamente como "latifundista". Sin embargo, el CDEM-Liwen desarrolló otra perspectiva de la trayectoria política de Venancio Coñoepan y la Corporación Araucana, reconsiderando sus intenciones y propuestas, al parecer, más comprometidas con la búsqueda de espacios de autonomía administrativa mapuche (Ancán 2012).

${ }^{4}$ Una de las características más importantes de los movimientos indígenas, es la construcción de una memoria histórica antigua y muy arraigada. Para el caso del movimiento mapuche, ésta no tiene comparación a la del resto de los grupos históricamente oprimidos en Chile. La memoria histórica del pueblo mapuche se transmite de forma ancestral, por lo que pertenece al patrimonio inmaterial de su cultura. El movimiento mapuche interpela constantemente la memoria en una construcción constante de su propia inteligibilidad y la del "otro" (Toledo 2007). Las diversas estrategias y proyectos históricos -entiéndase también diversos tipos de organizaciones-, surgen, precisamente, de las lecturas y conclusiones que los sujetos formulan en una tensión continua entre pasado y presente. En la cultura mapuche, memoria y territorio son dos elementos inseparables del rakizuam, por ello, la memoria se convierte en un elemento clave para el movimiento en tres aspectos: en primer lugar, se encuentra en el centro de lo que implica la supervivencia étnico-cultural; en segundo lugar, sirve de escuela para el aprendizaje político que genera el movimiento; y, en tercer lugar, es vital en la reproducción de la conciencia "de sí" y "para sí" que mueve a sus militantes. En el último tiempo han contribuido a la reconstrucción de esta memoria diversos intelectuales, en especial mapuche.
} 
estructurales que permitieron su constitución. La excesiva atención en la historia del conflicto mapuche, aunque necesaria, ha imposibilitado a la mayoría de los autores para dar cuanta suficiente sobre lo que significó, en términos sociales y políticos, cuando esa historia se entrelazó, en un momento coyuntural clave, con la historia del movimiento campesino 5 .

No obstante, una excepción a la regla constituye un conocido trabajo de Alejandro Saavedra. Éste sostiene que la "cuestión mapuche" en la década del 60 y comienzos del 70 se encontró unida a las demandas campesinas, pues fue "un asunto étnico, un asunto campesino y un asunto político". A estos dos movimientos los unió una fuerte identidad múltiple tanto étnica como de clase. Esto significa que las preocupaciones, las demandas, los conflictos y las propuestas relacionadas con los mapuche "tenían que ver con lo étnico, con lo campesino y con lo político" (Saavedra 2002). A pesar de su esfuerzo, más allá de insistir en la identidad étnica y de clase existente entre mapuche y campesinos pobres (cuestión que quedaría confirmada en la serie de testimonios que aparecen en Carvajal y Peralta 2006; Correa, Molina y Yáñez 2005: 339-350), Saavedra no ha deja claro si la alianza mapuche-campesina significó lo mismo para ambos sectores, tampoco ha construido análisis suficientes que permitan aclarar bajo qué condiciones o ventajas y desventajas políticas, para mapuche y no mapuche, se dio esa alianza.

En una postura distinta a la anterior, Caniuqueo señala que identificar a los mapuche como aliados estratégicos de las clases sociales excluidas ha sido un discurso "impuesto desde la izquierda", pues para el mapuche la conciencia revolucionaria implicaría dejar de lado la conciencia de pueblo para convertirse en un "frente para la acción, o sea, en una de sus piezas en el ajedrez"; ser maniobrados por la izquierda. Además, indica que en la actualidad está la idea del mapuche como víctima; un derrotado que sólo se redimiría con la recuperación territorial. Esta lógica no daría cuenta de los liderazgos internos, los procesos de inserción, adaptación y participación dentro de las comunidades, o los procesos socioculturales que generó la migración, entre otros (Caniuqueo 2006: 172-173).

El autor reconoce que a lo largo del siglo XX las organizaciones mapuche constituyeron alianzas tanto con la izquierda como con la derecha, pero indica que lo que algunos autores identifican como mapuche de izquierda y de derecha (refiriéndose a Foerster 1983), sería sólo una visión parcial de los hechos, ya que en realidad, los mapuche de izquierda y derecha desarrollaban alianzas internas que escapaban a las ideologías y compromisos políticos. También señala que "a fines de los 60' pareciera ser que los partidos pasan a ser la estrategia para algunos mapuche que ven su inserción en ellos como un fin para hacer política ya no como pueblo, sino como clase (obreros)", pero cree que esto no fue una visión generalizada dentro de los mapuche y que, por otro lado, también existirían conflictos generacionales al interior del pueblo que provocaría virajes políticos en sus organizaciones. Las alianzas para el pueblo mapuche, concluye Caniuqueo, han sido meras tácticas, "medios para alcanzar objetivos". En el pueblo mapuche "prácticamente no existe una lealtad ciega para algo tan abstracto como una religión o un partido, esto no

\footnotetext{
5 Bengoa (1985 y 2002), Foerster y Montecinos (1988), Mallon (2004), Toledo (2006), Correa, Molina y Yáñez (2005), Correa y Mella (2009), entre otros, no dejan de reconocer los lazos que el movimiento mapuche construyó con los partidos de izquierda tradicional y con el movimiento de la Nueva Izquierda Latinoamericana durante el período de la Reforma Agraria, cuestión que se repetirá en la década de los 80.
} 
quiere decir que no existan militantes, parroquianos o personas que sigan rumbos propios" (Caniuqueo 2006: 174-196). Desafortunadamente el autor no presenta suficiente información empírica que permita despejar dudas sobre sus interesantes reflexiones.

En el presente artículo nos preguntamos por los cambios estructurales y coyunturales que habrían favorecido el estallido del conflicto mapuche-campesino, en especial, la alianza entre campesinos mapuche y no mapuche en la Araucanía. En otras palabras: ¿qué condiciones surgieron para permitir que una larga historia de abusos contra la etnia -la negación originaria como la llamó Tricot (2013)- se convierta, en los años de la Reforma Agraria, en el estallido del movimiento mapuche-campesino? Esto nos lleva, en segundo lugar, a preguntarnos por las alternativas de movilización que tuvo el movimiento.

Buscando avanzar en el estudio y comprensión del fenómeno, hemos recurrido a la teoría de los conflictos sociales; enfoque que nos ha permitido ampliar nuestros conocimientos. Abrimos nuestras reflexiones considerando el siguiente supuesto teórico: difícilmente un movimiento social logrará convertirse en un 'gran movimiento' si no entra en una coyuntura favorable, o si no existen condiciones objetivas que permitan que estalle el conflicto sobre el cual radica su razón de ser, o si no es capaz de movilizar los recursos que ofrece el contexto sociopolítico (Olson 1965; Tilly 1978). La teoría racionalista de los conflictos sociales, sostiene que los conflictos entran en una etapa de estallidos social cuando quienes se sienten afectados por alguna situación que consideran desigual, amplían las posibilidades de resolución. Luego de una lectura de sus posibilidades de éxito, los afectados capitalizan la constitución de un escenario sociopolítico favorable a sus objetivos. Esta lectura, por lo menos medianamente informada, brindaría a los actores sociales cierta expectativa fundada en que la movilización entregaría beneficios objetivos (Lorenzo 2001: 38-42).

La constitución de un escenario sociopolítico más favorable a los movimientos sociales se conoce como Estructura de Oportunidades Políticas (EOP). Las EPO surgen cuando el entorno político o el sistema político influyen catalizando la acción colectiva. Ello no implica necesariamente que los resultados sean positivos para quienes se movilizan. Este escenario puede abarcar diversas dimensiones, entre otras, el grado de apertura del sistema político institucionalizado, los cambios que se producen en el sistema electoral; la inestabilidad en las alienaciones de las élites; la posibilidad o no de contar con el apoyo de un sector de las élites, la capacidad estatal para reprimir o la tendencia a hacerlo (Mc Adam, et. al. 1999; Tilly 1995; Tarrow 2004).

Sostenemos que entre enero de 1967 y el 11 septiembre de 1973, maduran una serie de fenómenos en el ámbito político, ideológico y social, que provocarían el surgimiento de una EOP muy favorable a los movimientos sociales indígenas y no indígenas. Con la llamada Revolución en Libertad, del gobierno democratacristiano, y luego con el triunfo de la Unidad Popular, los sectores sociales históricamente marginados (principalmente campesinos, pobladores, obreros) creyeron que había llegado la hora de "cambiar las cosas" y buscar la manera, como se decía entonces, de "tomar el cielo por asalto".

En el caso de los campesinos, tanto mapuche como no mapuche, la demanda por la tierra nunca tuvo en la historia de Chile un momento más promisorio que aquel brindado por la coyuntura 1967-1973. En ella coincidieron simultáneamente dos grandes fenómenos catalizadores de conflictos: a) la institucionalización de una profundización democrática en 
dos esferas: la democracia ciudadana-electoral y la democratización de la propiedad privada. Ya que a partir de la segunda mitad del siglo XX, paulatinamente el Estado implementa políticas que amplían estos aspecto de la democracia al permitir la inclusión y organización ciudadanía a los sectores campesinos, con medidas como el voto universal (1958) y la organización campesina, lo que se torna más efectivo con la dictación del corpus legal que acompañaba a la Reforma Agraria en 1967, la cual, a su vez, afectó positivamente la democratización de la propiedad privada (Gómez Leyton 2003: 53; Gómez Leyton 2004: 327-353); y b) la formación de una nueva ideología revolucionaria de transformación capitalista, tras el giro que asumen el MIR y el Partido Socialista al adoptar el principio de la lucha armada como vía de construcción socialista (Goicovic 2010: 64), lo que se sumaría a otros hechos nacionales e internacionales de marcada connotación ideológica. Todo ello, como veremos luego con más detención, ocurrió también en 1967. Ambos fenómenos (la ampliación democrática y las transformaciones en el plano ideológico) dieron origen a una EOP favorable al movimiento social en general y afectaron significativamente al movimiento indígena y campesino, pues estos últimos encontraron un momento único para constituir alianza y ampliar su estrategias de movilización social.

Por tanto, sostenemos que los cambios sociales y del Estado ocurridos a partir de la segunda mitad del siglo XX y que vinieron a madurar en 1967, serían claves para entender con mayor claridad los convulsos años de la Reforma Agraria. Las trasformaciones sociopolíticas de aquel año, abrirían una primera fase de democratización ciudadana y del derecho a la propiedad privada que, posteriormente, el gobierno de la Unidad Popular profundizará y ampliará hacia otras áreas de la economía capitalista, como la minería, la industria y el sector financiero nacional y exterior (Gazmuri 2000), en lo que identificamos como una segunda etapa de ampliación democrática (Gómez Leyton 2004: 327-353; Gómez Leyton 2010: 49-56).

En medio de este escenario, mapuche y campesinos hicieron lo que estuvo a su alcance para transformar su situación de marginalidad y exclusión histórica. La heterogeneidad de programas y compromisos ideológicos que surgieron al interior del movimiento, marcaron las pautas de división interna, pues los sectores se organizaron para actuar dentro de las dos únicas alternativas de movilización posible: ya sea dentro de los marcos legales e institucionales vigentes (lo que toleraba o permitía el régimen político, el Estado de derecho y los gobiernos democráticos), o fuera de pestos marcos. Por ello hablamos de la emergencia de un movimiento mapuche-campesino institucionalista (o movimiento menos radicalizado, vinculado a los partidos tradicionales) y de la emergencia de un movimiento mapuche-campesino no institucionalista (o movimiento radicalizado, vinculado a la Nueva Izquierda) ${ }^{6}$.

En primer lugar, presentamos una breve revisión histórica del conflicto mapuche y del conflicto campesino para luego, en segundo lugar, explicar la conformación de una EOP favorable a los movimientos mapuche y campesino y a la constitución de la alianza

\footnotetext{
${ }^{6}$ Una de las características de los movimientos sociales casi sin excepción, es que suelen experimentar divisionismos internos, según los diversos programas, proyectos e intereses de los sujetos que los componen. El movimiento mapuche y el campesino nunca han sido la excepción (Tricot 2013). En ellos se aprecian distintos proyectos, programas, estrategias y formas de relacionarse con el Estado y la sociedad chilena, según cada organización y comunidad.
} 
entre ambos. Esta EOP tuvo su origen en los cambios producidos en el sistema electoral en 1958, para desarrollarse posteriormente, a partir de 1967, en dos etapas, la primera en el gobierno de Frei y la segunda en el de Allende; pero ambas en el contexto que brindó la Reforma Agraria. En tercer lugar, revisamos las movilizaciones del movimiento mapuchecampesino institucionalista y del movimiento mapuche-campesino no institucionalista. Y, por último, concluimos con unas reflexiones finales.

Por otro lado, desde lo metodológico nuestra propuesta presenta un análisis transdisciplinar, una transmutación entre la etnohistoria, la politología y la sociología. No se analizan los procesos histórico-políticos e histórico-sociológicos como parte de una continuidad lineal (que constituye una descripción narrativa de análisis cronológico), sino, como una suma de momentos concretos. El momento concreto se ubica en la corta duración. Sin embargo, a diferencia del acontecimiento, o corta duración que señala Fernand Braudel (1970: 60-81) -que constituye cualquier hecho breve que se presenta como resultado de una causalidad sin distinción de su tipo-, queremos diferenciar el momento concreto como aquel "acontecimiento" surgido como resultado de una serie de discusiones y confrontaciones al interior de cada sector del movimiento, o de los sectores que dividieron a la clase política, e incluso, los resultados momentáneos que surgieron de las acciones o acuerdo entre el movimiento y la clase política. Así, las movilizaciones, la firma de un acuerdo, la dictación de alguna ley, etc., los hemos interpretado como el resultado parcial de múltiples tensiones, conflictos y acuerdos internos que los actores logran, en un momento concreto determinado, cristalizar en términos de causalidad. Entendemos que dicha causalidad no surgió como la formula esperada que resolvería las disputas al interior de cada grupo de presión o entre éstos y los grupos dominantes.

Lo anterior requirió de dos puntos de vista analíticos: el descriptivo, que implicó estudiar cuidadosamente un momento o acontecimiento para describirlo, considerando los actores y el contexto socio-político; y es el comprensivo, donde el análisis fundamental fue la relación entre los actores, ubicándolos dentro del marco de mediaciones institucionales que bridaba el régimen político y el modelo económico. El análisis de cada momento concreto representó una hipótesis a verificar. La verificación de las hipótesis, mediante la sumatoria de los momentos concretos, nos permitió identificar una tendencia, que representa un patrón de conducta de parte de la clase política dirigente y del movimiento. La revisión de este patrón permitió, en definitiva, revisar nuestras hipótesis de investigación.

\section{La marginación mapuche y campesina como origen del conflicto. Una breve revisión}

No se debe perder de vista que el conflicto Estado chileno-pueblo mapuche tiene su origen en lo que la historiografía tradicional denominó como "Pacificación de la Araucanía" (1862-1883), la cual, en realidad, fue una guerra de ocupación territorial que permitió al Estado chileno rematar y vender las tierras de la Araucanía, al sur del río Biobío, a colonos extranjeros y nacionales. Estas tierras comprendían una porción del territorio ancestralmente ocupado por mapuche a ambos lados de la cordillera de Los Andes muchos siglos antes de la conquista española, también es significativo que sobre las 
mismas existían acuerdos jurídico-fronterizos, denominados parlamentos, instituidos entre la Corona Española y el pueblo mapuche y posteriormente entre éste último y el propio Estado chileno, cuya importancia, en definitiva, fue el reconocimiento del derecho de ocupación territorial indígena (Pichinao 2012; Mariman 2012; Zabala 2008).

A partir de la Pacificación de la Araucanía los mapuche fueron obligados a vivir en reducciones comunitarias designadas mediante Títulos de Merced (1866 y 1884), lo que transformará significativamente su cultura y atentará contra su subsistencia. A partir de entonces se comenzó a constituir el latifundio en la región, ya que a lo largo del siglo XX las comunidades mapuche se vieron envueltas en disputas por la defensa de las tierras designadas en los Títulos de Merced, las cuales comenzaron a ser ocupadas ilegalmente por terratenientes inescrupulosos. Los medios de usurpación eran generalmente fraudulentos y violentos; los terratenientes hacían uso de la fuerza en medio del desdén e incluso complicidad de las autoridades y Juzgados de Indios, que rara vez hicieron justicia. A ello contribuyó la dictación de las leyes de división de las tierras comunitarias (1927, 1931 y 1979), que facilitaron su venta, muchas veces ilegal, y los ilícitos que extendieron el latifundio ${ }^{7}$. Este proceso fue empobreciendo a los mapuche cada vez más, mientras el Estado muy poco se preocupó por implementar medidas reparatorias. Debido a la estrechez de la tierra y la marginación económica, social y política, gran cantidad de mapuche debieron emigrar, generalmente a la capital, o trabajar en los fundos de sus propios usurpadores ${ }^{8}$.

En este escenario, desde comienzos del siglo XX los mapuche se organizaron bajo el alero de diversas instituciones con objeto de que las autoridades se comprometan con sus demandas y lograr así transformar el Estado o su relación con éste. Estas organizaciones propusieron alternativas de solución al conflicto mapuche que fueron muy disímiles unas de otras, pues, por ejemplo, comprendían desde la asimilación e integración total del mapuche con la sociedad chilena, lo que implicaba la desintegración de las comunidades y de la cultura mapuche (alternativa "pesimista", propuesta por Manuel Manquilef y los líderes mapuche y no mapuche que fundaron en 1910 la Sociedad Caupolicán, idea que también compartían la Iglesia Católica y el Estado), hasta, en el otro extremo, la construcción de un fuerte identitarismo mapuche, con el que se buscó el resguardo de las tierras comunitarias, la cultura y raza (alternativa que inicialmente fue defendida por Manuel Aburto Panguilef, presidente y fundador, en 1922, de la Federación Araucana) (Foerster y Montecinos 1988; Órdenes 2013).

Por su parte, las condiciones políticas y sociales del campesinado en general, aunque distintas a los mapuche de las comunidades, tampoco fueron favorables. No se puede

\footnotetext{
${ }^{7}$ La mayor cantidad de litigios por usurpaciones de tierras indígenas proviene de las comunidades divididas por las leyes de 1927 y 1931. Al dividirse las comunidades y otorgarse títulos individuales de dominio, se produjeron ventas fraudulentas bajo presión, arriendos transformados en compra-venta y otros latrocinios. "Las comunidades divididas de la Provincia de Arauco y Malleco son actualmente las que tiene mayores conflictos de esta naturaleza. Además, no se cumplió con el objetivo que los defensores de las divisiones señalaban: superar la pobreza de los indígenas que viven en comunidades" (CVHNT 2003a: 407).

${ }^{8}$ Sobre estos temas existe abundante literatura; ver, por ejemplo: José Bengoa (1985); Jorge Pinto (2002), "Epílogo"; José Bengoa (2002); Alejandro Saavedra (2002), capítulos Uno al Cinco; Informe de la Comisión Verdad Histórica y Nuevo Trato a los Pueblos Indígenas (2003); Martín Correa, Raúl Molina y Nancy Yáñez (2005); Mariman P. et al, (2006); Martín Correa y Eduardo Mella (2009), entre otros.
} 
apreciar a lo largo del siglo XX una mejora sustantiva en salarios y regalías para aquellos trabajadores que se encontraban en las capas inferiores del inquilinaje, mucho menos para los peones o asalariados no inquilinos. Esta disparidad respecto a la mano de obra urbana, donde sí se apreció una mejora de sus condiciones contractuales, no fue para nada casual; reflejó un proceso inducido políticamente, en el que participó todo el espectro partidista para excluir sociopolíticamente al campesinado de las conquistas sociales de los obreros urbanos. La finalidad de esta exclusión, fue sostener el proceso de industrialización nacional urbana que puso en marcha el Frente Popular (1936-1941) y siguieron los demás gobiernos hasta la reforma agraria de Eduardo Frei Montalva (Santana 2006: 169-187; Loveman 1971; Loveman 2000: 159-163). Ello, a la larga, impidió al movimiento campesino tener la fuerza suficiente y su escasa relevancia imposibilitó incluso establecer alianzas con el movimiento mapuche.

En efecto, a fines de la década de 1930 los partidos políticos negociaron con las organizaciones del empresariado y deciden postergar la Reforma Agraria y la sindicalización campesina. Pese a que los partidos Comunista (PC) ${ }^{9}$ y Socialista (PS) contemplaban estos avances en sus propuestas programáticas iniciales, en 1938 llegaron a un acuerdo con la Sociedad Nacional de Agricultura con el objeto de asegurar el apoyo de la gremial al proyecto de industrialización propuesto por el Frente Popular (Áffonso, et al. 1970: 31ss; Drake 1978: 218ss; Santana 2006: 169-187). A cambio de ese apoyo, los partidos de izquierda se comprometieron a no impulsar la Reforma Agraria ni la sindicalización de los trabajadores agrícolas. Por el solo hecho de su enrome peso numérico, los trabajadores del campo representaban una fuerza susceptible de modificar los equilibrios políticos en el país y podían poner en peligro los supuestos del proyecto industrializador (Santana 2006: 179; Gómez Leyton 2004: 183-200) ${ }^{10}$. En 1973 José Bengoa se refirió a la exclusión ciudadana del campesinado:

La presión campesina en Chile se viene haciendo sentir con intermitencias desde hace mucho tiempo. El proletariado industrial conquistó su derecho a sindicalizarse en la década del veinte. Este derecho le fue negado al campesinado. Cada cierto tiempo se hacía oír la presión campesina a través de organizaciones ilegales que por lo general eran reprimidas violentamente. La organización campesina era siempre negociada y postergada en las transacciones de la politiquería criolla. Sin embargo, las condiciones de vida, el abandono, la migración hacia las ciudades, etc... fueron preocupando a los sectores dominantes. La movilización del campesinado no tenía marcos de expresión definidos legalmente. Pequeños paros, cartas al Presidente protestando por las malas

\footnotetext{
${ }^{9}$ En el caso particular del PC, recordemos que su compromiso casi irrenunciable con las directrices del Komintern en distintas partes de América Latina, lo aisló del campesinado e impidió construir proyectos de intervención como en el caso de los trabajadores urbanos, debido a que los campesino no eran considerados propiamente como proletarios (Angell 1997: 76-95).

${ }^{10}$ El Censo de 1930 registró un 50,6\% de población rural. En las provincias del sur esa cifra aumentaba: 71,4\% en Biobío, 73,7\% en Cautín, 67,4\% en Valdivia, 83,5\% en Chiloé y 78,9\% en Aysén (Censo 1930: 5155). Para el Censo de 1960 la migración campo-cuidad había provocado que la población rural descienda al $31,8 \%$. En las provincias del sur esa disminución estaba levemente por debajo de la media nacional. En Arauco la población rural fue de un 64,2\%, en Biobío 62,8\%, en Malleco 55\%, en Cautín 61,2\%, en Valdivia 56\%, Osorno 53,8\%, en Llanquihue 58\%, en Chiloé 77,8\%, y Aysén 47,1\% (Censo 1960: 123).
} 
condiciones de vida, huelgas esporádicas reprimidas por ilegales, peticiones de regalías y salarios, etc., muestran superficialmente el descontento que se gestaba en el campo. El descontento tenía su válvula de escape en las migraciones a las ciudades ${ }^{11}$.

Aunque escaza, la información disponible para antes de 1932 muestra el desarrollo de oleadas sucesivas de acción reivindicativa campesina, "principalmente en las zonas localizadas en la periferia de algunas grandes ciudades" (Santana 2006: 175). Sin embargo, la exclusión institucionalizada del campesinado y la represión de sus sindicatos impidieron, entre otros factores, luego de los sucesos de la masacre de Ranquil (1934) ${ }^{12}$, mayores acciones por parte del movimiento campesino chileno.

La historia de esta exclusión es poco conocida. El 28 de marzo de 1939, poco después de comenzar el gobierno del Frente Popular, fue promulgado el Decreto $\mathrm{N}^{\circ} 34$ sobre la "organización sindical del campo", con objeto de abolir las disposiciones del Código del Trabajo (1925) para los trabajadores rurales, al mismo tiempo que se suspendió la constitución de nuevos sindicatos campesinos. A pesar que se indicó que era un decreto provisorio, en tanto se discutía una ley en el Parlamento, éste tuvo vigencia hasta 1947, fecha en que se promulgó la Ley de Sindicalización Campesina $\mathrm{N}^{\circ} 8.811$, que, en la

\footnotetext{
${ }^{11}$ Loveman, en El campesino chileno le escribe a su excelencia (1971), presenta una cantidad impresionante de cartas de campesinos del centro, sur y sur-austral dirigidas los presidentes de la República, desde el gobierno de Pedro Aguirre Cerda (1938-1941) hasta el de Frei Montalva, con demandas laborales contra los terratenientes. Entre las materias se encuentran el no pago de salarios y leyes sociales, reclamos por aumentos salariales y malos tratos a los trabajadores y sus familias. Los presidentes, en muchos casos, remitieron las demandas al inspector del trabajo de cada departamento. No deja de ser interesante que entre los remitentes figuren incluso trabajadores de sectores muy aislados del extremo sur, la Araucanía y otras zonas, lo que indica que encontraron la manera de hacer oír sus demandas a la máxima autoridad del país, aunque no lograron soluciones definitivas. Así las cosas, la supuesta subordinación del campesinado al paternalismo del patrón, no sería más que una imagen errónea de sumisión y estancamiento por parte de un campesinado también supuestamente clientelar. Sostenemos que tal subordinación no debe extrapolarse a todo el campesinado, sino más bien, a las capas superiores del inquilinaje, aquellos que en la Reforma Agraria se mostraron, como señalaban los terratenientes, “contentos con el patrón” (Órdenes y Díaz-Diego 2015). José Bengoa cambiará más tarde su postura inicial respecto al campesinado en El poder y la subordinación. Historia social de la agricultura chilena, Tomo I (1988), sostiene que fueron los partidos políticos y movimientos urbanos quienes provocaron los cambios modernizantes en el campo en el contexto de la Reforma Agraria. Su tesis principal indica por un siglo y medio luego de la Independencia, los sectores campesinos mostraron obediencia ciega al patrón, quienes controlaban no sólo al inquilinaje sino también los pueblos pequeños y al Estado. La sobre valoración de ciertos fenómenos de la tradición campesina, como el clientelismo, impiden a Bengoa considerar los mecanismos de resistencia de la mano de obra rural para hacer frente a la exclusión sociopolítica que hemos explicado. Por otro lado, también no deja de ser interesante que las mismas demandas sociales de los trabajadores rurales del valle central, aquejaban a los de La Araucanía.

${ }^{12}$ La zona precordillerana del sur de Chile había experimentado desde principios del siglo XX una elevada presión por el desequilibrado reparto de las tierras y las difíciles condiciones de vida de las comunidades mapuche y los campesinos más pobres que, en el invierno de 1934, originó el levantamiento y posterior masacre de Ránquil, un sector rural del municipio de Lonquimay (actual provincia de Malleco, IX región de La Araucanía) en el que campesinos, habitantes mapuche y obreros de los lavaderos de oro terminaron organizando una revuelta social después de que los distintos poderes del Estado y empresas de la zona, como la Sociedad Puelma Tupper, desoyeran sus peticiones de mejoras salariales para unos y acceso a tierras de trabajo para otros. El cuerpo de Carabineros y las Milicias Republicanas terminaron aplastando violentamente la revuelta en julio de aquel año (Uliánova 2003)
} 
práctica, impidió la sindicalización campesina y entregó facultades a los empleadores terratenientes para despedir a los dirigentes (Santana 2006: 183; Loveman 2000: 159-163). Al año siguiente, Gabriel González Videla promulga la Ley de Defensa de Permanente de la Democracia $\mathrm{N}^{\circ}$ 8.987, quedando proscrito el PC, lo que también afectó a la debilitada organización campesina.

\section{La constitución de la EOP: los cambios democráticos, institucionales e ideológicos}

Las cosas comenzaron a cambiar en 1958, año de dictación de la Ley de Reforma Electoral, que otorga derecho a voto a los analfabetos, con lo que muchos trabajadores rurales comienzan a participar, por fin, de la vida política-electoral convirtiéndose recién en ciudadanos. Además, esta ley establece la "cédula única" para todos los votantes, con lo que el voto se hace libre y secreto, reduciendo el cohecho y la posibilidad de controlar la decisión de los electores. Ese año también fue abolida la Ley de Defensa de Permanente de la Democracia.

Posteriormente, la llegada de la Democracia Cristiana (DC) al gobierno con Frei Montalva marcó en el sector rural el inicio de un proceso sistemático de redistribución del ingreso, de los recursos estatales y de la tenencia de tierra, su objetivo era frenar la importación de productos agrícolas básicos, como el azúcar y los cereales, reducir los costos de producción y precios finales de los productos rurales y así fortalecer el proceso industrializador en su conjunto, tanto urbano como rural. Para ello había que modernizar al campo, considerado como el sector más atrasado y postergado del país según los diagnósticos de la época ${ }^{13}$. Se entendía que el Programa Social del gobierno de Frei, Reforma Agraria y "promoción popular" para el caso de los desposeídos en los centros $\operatorname{urbanos}^{14}$, no alcanzaría algún éxito si no se lograban concretar las políticas redistributivas

\footnotetext{
${ }^{13}$ La pobreza campesina se encontraba bien constatada en uno de los diagnósticos avalaron la profundización de la Reforma Agraria. Como parte de los compromisos adquiridos por el Estado chileno en el marco de la Alianza Para el Progreso, tras la firma de la Carta de Punta del Este (1961), el Comité Interamericano de Desarrollo Agrícola (CIDA), elabora a petición del Gobierno de Chile un informe titulado, Chile: Tenencia de la Tierra y Desarrollo Socioeconómico del Sector Agrícola (1966), en él se efectuó un acucioso estudio de la estructura de la tierra en el sur del país y se comprobó las condiciones en que vivían los campesinos pobres, por lo que sugirió algunos lineamentos generales para una nueva etapa de reforma en la tenencia de la tierra. Bengoa indica que, "las explotaciones con más de 200 hectáreas equivalían al 11\% de las exportaciones del país y controlaban el $88 \%$ de la tierra. En la Zona Central esta situación era aún más grave, un $8 \%$ de las explotaciones controlaba el $80 \%$ de la tierra. Junto a la concentración se encontraba la fragmentación del minifundio. En 1965 según el censo nacional agropecuario existen 730 explotaciones agropecuarias de una extensión superior a las 5.000 hectáreas físicas. Estas explotaciones contenían más de 10 millones hectáreas agrícolas, esto es, casi un 50\% de las tierras agrícolas del país. Para comprender estas cifras digamos que el total de la superficie agrícola del país es de 20.400.000 de hectáreas y los casi 300 mil mapuches del sur de Chile por ejemplo, viven en menos de 500 mil hectáreas. Junto a ellas coexistían ligadas funcionalmente miles de pequeñas propiedades, 45.233 propiedades menores de una hectárea, 156.769 propiedades de menos de 10 hectáreas" (Bengoa 1983: 25-26).

${ }^{14}$ El programa social de la DC, influido por las ideas del sacerdote jesuita Roger Vekemans, se planteó la política de "promoción popular" como estrategia para erradicar la marginación social y la pobreza (Goicovic 2000: 113; Gazmuri 2000). En él integraba la tradición estatista de las décadas del cuarenta y cincuenta, con
} 
y de aumento de la capacidad de consumo para sectores urbano y, además, modernización del campo y de repartición de la gran propiedad de la tierra entre el minifundio y campesinos no propietarios (sin importar su origen étnico) Para ello, debían ampliarse los canales de participación ciudadana, para permitir a la sociedad civil acceder a las políticas del Estado subsidiario e interventor dentro de los marcos que brindaba lo que se conoce como matriz sociopolítica clásica, estatal-nacional-popular ${ }^{15}$. Por este motivo, una de las primeras tareas será estimular el desarrollo de cooperativas y sindicatos campesinos, muy necesarios para la asignación de tierras y recursos a mapuche y no mapuche, ya que estas políticas, como era el propósito de la Reforma Agraria, no contemplaron la diferenciación étnica de sus miembros (Toledo 2006: $31-38)^{16}$. Todo ello, a la larga, afectó positivamente tanto a la democracia política como a la democratización de la propiedad privada.

Sin embargo, no era posible para la DC llevar a cabo un amplio programa de reforma a la tenencia de la tierra, sin afectar el régimen de propiedad privada de la misma. Consagrado y bien resguardado en la Constitución de 1925, éste debía ser modificado. Previamente, durante el gobierno Jorge Alessandri, se había promulgado la Ley 15.295 (1963), que sometía el traspaso de la propiedad privada rural a un trámite bastante burocrático, haciéndolo casi inoperante en la práctica, por lo que Frei estaba obligado a insistir sobre ese punto intentando llegar a un acuerdo con los terratenientes y el Parlamento. A pesar de la aguda resistencia de los sectores conservadores y la división del centro político, específicamente dentro del Partido Radical, tras una votación muy discutida la DC logrará reformar la Constitución con la Ley 16.615 (20 de enero de 1967) (Aylwin et. al. 1984: 262-263; Órdenes y Díaz-Diego 2015). Con ésta se puso fin a la protección constitucional del derecho de propiedad privada, posibilitando su democratización. La reforma de Frei constituyó un paso necesario para la institución de la Reforma Agraria.

Luego, en abril de 1967, el gobierno dictó una nueva la Ley de Sindicalización Campesina, 16.625, que permitió, por fin, la sindicalización de los obreros del campo. Ello facilitó la participación y unión activa del campesinado en la Reforma Agraria y en los procesos electorales.

En el mismo año, julio de 1967, se promulga la nueva Ley de Reforma Agraria, 16.640, impulsándola legal y legítimamente para erradicar el minifundio e iniciar la

la reivindicación de justicia social propia del pensamiento católico (el comunitarismo) y las propuestas reformistas de la Alianza para el Progreso. Chilenización del cobre, Reforma Agraria, promoción de la educación y la salud, eran los puntos sobresalientes de un programa que se ajustaba a las propuestas ampliamente difundidas por la CEPAL. La oposición de izquierdas (liderada por Allende en las elecciones del 64) también recogía muchas de estos cambios, aunque en una versión más radicalizada. El programa de la DC, como señala Gazmuri, "tenía el mérito inmediato de sonar atractivo, y el inconveniente de largo plazo de ser algo indefinido y difícil de traducir en prácticas e instituciones operantes" (citado en Romero 2003: 3). La diferencia que Frei marcó insistentemente, es que la DC haría una "Revolución en Libertad", lejos de la "dictadura marxista". Esto atrajo a los jóvenes revolucionarios y cristianos, ese antimarxismo convirtió a la Democracia Cristiana en la menos mala de las alternativas para el tercio de votantes de la derecha (Gazmuri, 2000).

${ }^{15}$ Sobre la matriz estatal-nacional-popular, ver Manuel Antonio Garretón, et. al. América Latina en el siglo XXI. Hacia una nueva matriz sociopolítica, Capítulos I y II. pp. 15-38.

${ }^{16}$ Es bien sabido que la Reforma Agraria no contempló inicialmente el problema mapuche, ya que se entendía la que superación de la pobreza del sector pasaba por la solución del problema campesino en su conjunto. Sobre legislación de Reforma Agraria ver Huerta (1989: 204 y 277) y Correa, Molina y Yáñez (2005: 71-89). 
distribución de la propiedad agrícola entre los no propietarios. Se entendía que ello, junto a la asistencia del Estado, era vital para disminuir la pobreza y aumentar la productividad agrícola. Con la nueva Ley, se puso fin a un breve período de reforma a la tenencia de la tierra de muy poca significación, que partió en 1962 bajo el gobierno de Jorge Alessandri y que se ha denominado irónicamente como "Reforma de los Maceteros".

La participación social y política del electorado campesino se vio fuertemente incrementada a partir de 1967, una vez dictada la nueva Ley de Sindicalización Campesina, que acompañaba a la nueva Ley de Reforma Agraria. Tal es así, que en 1963 sólo había unos 1.500 campesinos sindicalizados, una década más tarde, en 1972, esa cifra había aumentado a 282.617. Así mismo, entre 1967 y 1973, la participación electoral aumentó significativamente, pasó de 3.074.000 votantes, en las elecciones municipales de 1967, a 4.510.000 en la elección parlamentaria de marzo de 1973 (Gómez Leyton 2004: 328).

Esto indica, que tras la inclusión social y política del campesinado el número de votantes creció un 46,7\% en apenas seis años, equilibrando los procesos electorales a favor del centro político y los partidos de izquierda, pues con este nuevo corpus legal se redujo el tradicional control e influencia de los sectores conservadores (partidos políticos y terratenientes) en las zonas rurales, estimulando la competencia electoral. A su vez, el campesinado encontró incentivos para participar en los partidos por medio de los sindicatos, en tano que éstos ven en los campos una nueva y gran fuente de votos. Otro factor que favoreció el interés de los partidos por el reclutamiento del campesinado, fue la generación de un amplio consenso sobre los problemas estructurales que evidenciaba el sector rural, los que debían ser resueltos por medio de la Reforma Agraria (Barraclough y Fernández 1974; Ortega 1987; Huerta 1989; Baland y Robinson 2004; Gamboa 2011). En un trabajo reciente, Avendaño (2014) indica que rápidamente los partidos se orientaron a la tarea de representar al campesinado en general.

El PDC ya contaba con experiencia debido a su vinculación con el Instituto de Educación Rural (IER), y con otras organizaciones que surgieron luego de que fuera derogada la Ley de Defensa Permanente de la Democracia, en 1958 (...). La principal Confederación que controlaba el PDC se denomina Triunfo Campesino, aunque también poseía otras dos, Libertad y Sargento Candelaria, lo que muestra las diferencias que existían sobre la política agraria al interior de ese partido. El PC y el PS crean la Confederación Ranquil, que llega a ser bastante influyente en las movilizaciones que se desencadenan en el período 1967-1970. Hacia fines de los años sesenta el Partido Nacional (PN) intenta representar, sin éxito, a organizaciones campesinas, pese a la importante presencia que este partido tendrá en las organizaciones de empresarios agrícolas. En esa misma época se funda el MAPU, la facción que se escinde del PDC, y que promueve la creación de la Confederación Unidad Obrero Campesina (Avendaño 2014: 105).

El cumplimiento de parte importante del Programa Frei en el campo, estimuló significativamente la influencia de la DC, convirtiéndose en partido hegemónico ${ }^{17}$. En tanto

\footnotetext{
${ }^{17}$ A mediados de los años 60 el sistema de partidos sufrió cambios significativos, dado los rápidos éxitos electorales de la DC en los años que siguieron a su fundación en 1957, que marginaron en gran medida a los
} 
que la derecha, representada por el Partido Nacional (PN), quedó marginada de su influencia en el sector rural. Con apenas un $0,9 \%$ de afiliados campesinos fracasó su estrategia de participación electoral.

\section{Cuadro $N^{\circ} 1$}

Confederaciones sindicales campesinas, 1970-1973

\begin{tabular}{|l|c|r|r|r|r|}
\hline \multirow{2}{*}{\multicolumn{1}{c|}{ Confederación }} & Vinculación & \multicolumn{2}{|c|}{1970} & \multicolumn{2}{c|}{1973} \\
\cline { 3 - 7 } & partidaria & $\mathrm{N}^{\circ}$ afiliados & \multicolumn{1}{c|}{$\%$} & $\mathrm{~N}^{\circ}$ afiliados & \multicolumn{1}{c|}{$\%$} \\
\hline Ranquil & PC-PS & 35.328 & 30.10 & 96.254 & 43 \\
\hline Triunfo Campesino & PDC & 53.930 & 45.90 & 66.146 & 29.7 \\
\hline Libertad & PDC & 24.854 & 21.15 & 44.260 & 19.8 \\
\hline Sargento Candelaria & PDC & 2.241 & 1.90 & 2.567 & 1.1 \\
\hline Unidad Obrero-Campesina & MAPU & --- & --- & 14.199 & 6.3 \\
\hline Provincias Agrarias Unidas & PN & 1.129 & 0.96 & 2.181 & 0.9 \\
\hline Totales & & 117.482 & 100 & 225.607 & 100 \\
\hline
\end{tabular}

Fuente: Avendaño 2014: 105.

Al finalizar su gobierno, Frei promulga la Ley 17.280, en enero de 1970, que introduce modificaciones a la Ley de Reforma Agraria, con objeto de acelerar el proceso y hacerlo más eficiente; pues permitió la inmediata toma de posesión de los predios; evitó la subdivisión de los mismos para evadir la reforma; amplió el universo de potenciales beneficiarios, permitiendo el acceso de campesinos que no poseían el carácter de inquilinos; buscó evitar la descapitalización de los predios expropiados y favorecía la continuidad productiva de los mismos; incorporó en la expropiación herramientas, maquinarias, utensilios, animales y otros bienes que fueran parte del predio expropiado y que sean necesarios; y, por último, fortaleció la organización campesina, permitiendo su asociación en federaciones y confederaciones. Meses antes de asumir Allende, con la ley 17.280, se aplicó de manera más eficiente la Reforma Agraria; de esta forma, la Unidad Popular contó con una base jurídica que le permitió llevar a cabo una reforma de importancia. El movimiento campesino, indígena y no indígena, hará lo posible por defender y participar del proceso.

En suma, de manera paulatina a partir de 1958, los campesinos pudieron hacer uso pleno de los derechos ciudadanos que la clase propietaria agraria les había negado durante décadas mediante el cohecho, el fraude electoral y las trabas institucionales tendientes a frenar la organización sociopolítica. Esta profundización democrática, según Gómez Leyton, terminaría por brindar las condiciones para que la democracia chilena se convierta, por primera vez en su historia, en una auténtica poliarquía (Dahl 1996), o sea, con

sectores conservadores. Entre fines de los 50 y 60, la DC se convirtió en el partido chileno con la mayor proporción de votos en el siglo $\mathrm{XX}$, en tanto que la izquierda fue el único segmento que retuvo y hasta incrementó levemente su proporción de votos durante los años del ascenso de la DC. Las cifras son elocuentes: en las elecciones a la cámara baja en 1957, la Falange y los conservadores social cristianos obtuvieron solo un 13,2\% de votos, pero en las elecciones subsiguientes, también parlamentarias, de 1965, la DC alcanzó un 43,6\%. Aunque esa cifra bajó en 1969 a un valor no despreciable de 29,8\%, el presidente Frei contó con un gran apoyo en el Senado durante los años de mayores reformas estructurales de su gobierno (Valenzuela 1995: 55-57). 
autoridades públicas electas, elecciones libres, imparciales y frecuentes, sufragio universal, derecho a competir por los cargos públicos, libertad de expresión, información alternativa y libertad de asociación ${ }^{18}$. Con la inclusión definitiva del campesinado en 1967, "el sistema político-democrático se volvió plenamente inclusivo" y se produce la disolución políticoinstitucional del pacto de dominación social que sostenía al Estado de subsidiario desde la década del treinta; hecho que, más tarde, conduciría a una profunda crisis de Estado, resuelta de la manera más dura por los militares y la oligarquía en 1973 (Gómez Leyton 2004: 328).

Por otro lado, en 1967 también ocurren transformaciones en el plano ideológico, tanto a escala nacional como internacional. Ese fue el año de la reforma universitaria. Este movimiento fue nuclear en la articulación del estudiantado universitario con las demandas obreras, barriales y campesinas de las regiones del centro y sur de Chile, como así también en el desarrollo de las organizaciones de izquierda. Hechos similares ocurrían en otros vecinos latinoamericanos, como Argentina, Brasil y México. Luego vino el mayo francés de 1968, donde el estudiantado universitario junto con el movimiento obrero y el Partido Comunista de Francia, entre otros, pusieron en jaque al gobierno de Charles de Gaulle.

También en el plano ideológico, a la discusión teórica y a los cambios sociopolíticos que impulsó el éxito de la Revolución Cubana, se sumarían, en agosto de 1967 en La Habana, la fundación de la Organización Latinoamericana de Solidaridad (que quedaría presidida nada menos que por Salvador Allende) y la muerte de Ernesto 'el Che' Guevara en La Higuera, Bolivia, el 9 de octubre de 1967.

En este escenario, también en 1967, una facción de la izquierda chilena considerará que la violencia revolucionaria constituye una estrategia legítima para poner fin a la dominación capitalista e iniciar la construcción del socialismo. En octubre de 1967, el Partido Socialista de Chile, en su XXII Congreso Nacional, postula que la violencia política debía ponerse al servicio de los sectores revolucionarios del país. Además, será en el III Congreso del MIR, realizado en diciembre de ese año, cuando el sector de inspiración castrista-foquista liderado por Miguel Enríquez, Bautista van Schowen, Luciano Cruz y Andrés Pascal, plantearán la insurrección popular armada como único camino para derrocar el régimen capitalista. En opinión de Goicovic, la "introducción de las formas armadas de lucha como estrategia de enfrentamiento con el Estado y las clases dominantes" constituye "una de las contribuciones teóricas y estratégicas más importantes del MIR al pensamiento revolucionario en Chile". Así, socialistas y miristas señalaron que el conflicto político se iba a resolver en forma violenta. En efecto, seis años más tarde de haber sido asumida por la izquierda revolucionaria la opción por la lucha armada, la violencia política se instaló en la sociedad chilena, "pero no fue la izquierdista sino la violencia política histórica, la tradicionalmente desarrollada por las clases dominantes la que se impuso en el país" luego de 1973 (Goicovic 2010: 64).

Como dijimos, a partir de la aproximación entre el MIR y comunidades mapuche nacerá en la provincia de Cautín el MCR, que será la más notoria de las organizaciones

\footnotetext{
${ }^{18}$ Ver la discusión que Gómez Leyton hace sobre este tema en, “¿Chile, un país democrático? Un modelo para su análisis histórico-político", en La frontera de la democracia: el derecho de propiedad en Chile, 19251973, 2004: 15-50.
} 
mapuche-campesinas que plantearon la vía insurreccional. El MCR disputaría los espacios de conquista ideológica en la Araucanía con otras organizaciones similares y con aquellas, como vimos, que nacían de los partidos con la constitución de sindicatos. En la mayoría de estas organizaciones participaban estudiantes y líderes del Movimiento Universitario de Izquierda (rama universitaria del MIR), estudiantes de la Universidad de Concepción, de la Izquierda Cristiana (IC), de la Federación Universitaria Indígena de Temuco, con un carácter menos revolucionario que otros movimientos, y algunos maoístas (Foerster y Montecino 1988: 285-358; Bengoa 2002: 117-158; Ruíz 2005). De esta manera se entrelazaban el movimiento universitario con el campesino e indígena mapuche, a la vez que los partidos políticos cometían por la conquista electoral e ideológica del sector rural.

En definitiva, al término del gobierno DC, las organizaciones mapuche y el movimiento campesino lograron establecer alianza. Ello no podía nada menos que haber sido estimulado por la coyuntura generada a raíz de los avances democráticos mencionados (democracia electoral, ciudadana y de la propiedad privada), junto a las transformaciones y hechos ocurridos en el plano ideológico; fenómeno que identificamos, con mucha notoriedad a partir de 1967, como la conformación de una EOP favorable al movimiento campesino e indígena. A partir de ese año, los grandes terratenientes estaban conscientes que la situación tenía que volver a sus cauces tradicionales y los mapuche, por su parte, entendieron que la historia les estaba tendiendo la mano. Sin embargo, con el gobierno de la Unidad Popular vendría en seguida una segunda etapa de ampliación democrática y profundización de la Reforma Agraria. De esta forma, el movimiento social y los terratenientes se enfrentaron en una lucha histórica, no sólo contra un adversario, sino también, contra el tiempo.

\section{La segunda fase de ampliación democrática: la constitución de la EOP en el gobierno "popular"}

Los grandes programas de reformas sociales y a la propiedad del gobierno de Frei fueron, en lo sustantivo, profundizados por Allende (Gazmuri 2000) en lo que identificamos como una segunda etapa de ampliación democrática (Gómez Leyton 2003: 53; Gómez Leyton 2004: 327-353); ésta, a diferencia de la anterior, sería ahora "popular". El triunfo electoral de la UP (4 de septiembre de 1970), significó el arribo de un gobierno de coalición de partidos de izquierda que se habían planteado como meta alcanzar el triunfo pleno del "poder popular". Ello se traducía, según el Programa de Gobierno UP, en "llevar a cabo los cambios de fondo que la situación nacional exige sobre la base del traspaso del poder, de los antiguos grupos dominantes a los trabajadores, al campesinado y sectores progresistas de las capas medias de la ciudad y del campo" (1970: 12). Para ello se consideraba necesaria la "toma en sus manos" (Ibíd.) del poder por parte del pueblo, pero para ello la UP contemplaba únicamente las formas y los espacios definidos por el Gobierno, dentro de los cauces legales. Según este Programa, la toma del poder consistía, en palabras de Iglesias,

esencialmente en la incorporación progresiva de los sectores populares a los distintos niveles de la administración del Estado, empezando por la entrada a la gestión de las 
empresas del Área de Propiedad Social, es decir, del sector nacionalizado de la economía, constituido a partir de la recuperación de empresas estratégicas del gran capital monopólico, extranjero y nacional; y en su participación activa en la vida política y social del país a través de organizaciones sindicales, cooperativas y Juntas de Vecinos (Iglesias 2015: 231).

En este contexto se dicta, en julio de 1971, una nueva Ley de Reforma Constitucional para afectar la propiedad privada, la Ley 17.450, que permitirá en lo inmediato acelerar la reforma a la propiedad de la tierra y concretar la nacionalización del cobre. En definitiva, con estos y otros cambios, el proyecto político de la UP buscaba alterar las relaciones de poder pero "actuando desde el Estado sobre la sociedad" (Garcés 2004). Se esperaba que los sectores populares fueran meros espectadores y de apoyo al proceso, no actores del mismo (Harnecker 2003). Con todo, a medida que se hacían manifiestas las contradicciones que contenía el proyecto de la UP -cuya singularidad consistía, en parte, en pretender superar "la dicotomía reforma/revolución" (Álvarez 2010: 237, citado en Iglesias 2015: 231)-, "los sectores populares radicalizaron las formas de acción previstas y ensayaron modos efectivos de poder popular que tendían a superar la tradicional división entre gobernados y gobernantes: se trató de los cordones industriales y de los comandos comunales" (Ibíd.). Ambas instancias de autogestión obrera, encabezadas por el MIR, contradecían la "revolución dentro de la legalidad" impulsada por la UP y la concepción misma de "gobierno popular". Eran los años del Pliego del Pueblo (octubre de 1972), que desarrollaba y concretaba las propuestas de "poder popular", apenas esbozadas en el Programa de Gobierno de la UP (Ibíd.).

Mientras tanto en el campo, junto a las tomas, corridas de cerco y ocupaciones, el MIR desarrollaba los Consejos Campesinos de "base popular". Con estas y otras acciones al margen de la legalidad, campesinos indígenas y no indígenas intentaban construir un poder paralelo al gobierno popular, al igual como lo hacía el movimiento social en sectores urbanos (Llanos 2009). De esta forma, en síntesis, con la UP culminaba una segunda fase en la conformación de una EOP, que se manifestó en la profundización de la democracia electoral, ciudadana y de la propiedad privada, junto a la proliferación de la ideología y acciones del movimiento de izquierda. Con estas transformaciones se resquebraja por completo el pacto de dominación que sostenía al Estado benefactor y de compromiso, el cual en parte descansaba en los acuerdos políticos que excluían a obreros y campesinos de la democratización de la propiedad privada y, para el caso de los campesinos, también del derecho a la organización y participación político-ciudadana; factores claves en el desarrollo de una democracia de mayor calidad (Gómez Leyton 2004). Tristemente, ello también preparaba la reacción oligárquica urbana y terrateniente que hizo frente a las conquistas sociales con un golpe de Estado.

El momento de la esperanza: estallido del movimiento mapuche-campesino

No es casualidad que el año 1967 estallen las tensiones acumuladas durante décadas en La Frontera. Los sectores movilizados, leyendo las señales de su tiempo, creyeron oportuno avanzar para sacar el mejor provecho posible al momento histórico que vivían. Estudiantes universitarios, intelectuales de izquierda, mapuche y campesinos, se constituyeron en 
aliados en su intento de transformación revolucionaria. La demanda más significativa para movimiento mapuche fue recuperar las tierras usurpadas de los Títulos de Merced, en tanto que para el movimiento campesino no mapuche demandaba "la tierra para el que la trabaja" (Bengoa 2002: 117-148; Saavedra 2002: 81-110). Además, a diferencia del campesino no mapuche, para el mapuche, la recuperación de la tierra representaba una cuestión que no necesariamente tenía que ver con hacer la revolución marxista, era la oportunidad histórica de recuperar lo que el winka les había quitado (Saavedra 2002: 97-99; Samaniego y Ruiz 2007: 325-400). Los límites de sus tierras estaban en la memoria de los abuelos, marcados por los ríos o esteros, como indicaban ellos y, también en muchos casos, en los papeles acumulados en el Juzgado de Indios donde rara vez se hizo justicia (Bengoa 2002 128). Recuperar la tierra para el mapuche significaba recuperar el territorio; era un tema de contraofensiva histórica.

Los testimonios indican que cuando comienza a configurarse un escenario sociopolítico más favorable al movimiento mapuche (poco antes 1967), éste empieza a reconstruirse en términos ideológico-programáticos con la colaboración de los sectores revolucionarios y logra agenciar políticamente su memoria histórica y también la de los campesinos pobres no mapuche para construir el gran movimiento (Carvajal y Peralta 2006). A este capital el movimiento sumó los espacios de ampliación democrática que le brindó el régimen durante Frei y Allende, logrando transformar esta batería de instrumentos, en una ruta de proyección histórica; en un futuro que se presumió esperanzador.

A la llegada de la UP, el movimiento mapuche-campesino se expresará de la misma forma que el resto de los movimientos sociales de la época, "en particular, en una de las dos tendencias políticas principales que existían en la izquierda, al interior de la UP y fuera de ella" (Saavedra 2002: 97). La primera tendencia se denominaba "reformista", por contraposición a las tendencias llamadas "revolucionarias". Ambas querían hacer la revolución socialista y juntas formaron la más significativa movilización de los sectores subalternos de toda la historia patria (Ibíd.). Por tanto, los grupos de izquierda, tanto fuera o como dentro de la UP, nunca pensaron en el movimiento mapuche como una "masa de maniobra" (como sostiene cierto pensamiento al interior de la derecha y algunos intelectuales como José Bengoa 2002: 152), sino que intentaron construir amplias movilizaciones sociales, que incluían a mapuche, campesinos, pobladores, intelectuales y trabajadores. Tampoco se propusieron "hacer nunca la revolución de inmediato", ya que las discrepancias en los sectores de izquierda referían a cómo avanzar mejor en la perspectiva de hacer la revolución socialista (Saavedra 2002: 99).

Lo anterior nos ayuda a explicar que dentro del movimiento existían posturas distintas; amplios debates sobre las estrategias o programas a seguir para alcanzar un mejor futuro y sobre qué futuro concreto querían alcanzar. Sostenemos que básicamente existían dos posiciones o sectores: el movimiento mapuche-campesino institucionalista, conformado por quienes confiaban en que la forma más legítima y segura de alcanzar las demandas del movimiento mapuche-campesino era negociando, con ayuda de los partidos, para lograr acuerdos con las autoridades y así transformar el Estado. Tal como lo había hecho el movimiento obrero, utilizando los instrumentos democráticos tradicionales y la forma institucionalizada de hacer política, amparado en el sindicalismo instituido en el Código del 
Trabajo a partir de la conformación del Estado de compromiso. De esta forma, partidos políticos, procesos eleccionarios, el Ejecutivo y Legislativo, eran considerados por esta posición del movimiento mapuche-campesino, como instrumentos claves frente a cualquier negociación. Sin duda, la ventaja política más significativa para esta corriente, constituía en lograr que sus candidatos llegaran al Parlamento o a las municipalidades, entendiendo que era necesario instalarse en el Estado para hacer los cambios "desde dentro". Contrario a esa postura se encontraba el movimiento mapuche-campesino no institucionalista. Este segundo sector se caracterizó por su posición insurrecta, pues desconfiaba de la política tradicional y estimaba que la vía revolucionaria "directa" era el único camino posible. Para ese sector las instituciones de la democracia tradicional podían ser prescindibles si se estimaba necesario, lo importante era actuar por ellos mismos: tomar la tierra para recuperarla de manos de los usurpadores y presionar a las autoridades para que consideren las demandas y procesos de lucha como legítimos. Éstos, ligados al MIR y organizaciones similares, creyeron que había llegado la hora de "tomar el cielo por asalto".

Tras la constitución de ambos sectores del movimiento mapuche-campesino, en muy poco tiempo se desarrolló un gran movimiento que, desde abajo, presionó al régimen político, al Estado de compromiso a y los señores de la tierra con demandas y movilizaciones propias, que se encontraban fuera de la agenda de gobierno y más allá de lo que los terratenientes podían tolerar. Sostenemos que las fronteras entre el movimiento mapuche-campesino institucionalista y el movimiento mapuche-campesino no institucionalista se pueden identificar más por sus marcos ideológicos, que por las estrategias de lucha implementadas de acuerdo a las lecturas que se hacían de la contingencia, ya que, muchas veces, el fin suele justificar los medios. También fue posible, como veremos, que una determinada organización se reconfigure en términos ideológicos y programáticos con objeto de permanecer en el tiempo o defender algunas de sus demandas, pasando, tras una decisión pragmática, de un lado a otro de la política institucionalizada.

\section{Desde abajo y desde dentro de la política tradicional: el movimiento mapuche- campesino institucionalista}

Mucho antes de que exista una alianza entre mapuche y campesinos, al comenzar el siglo XX se constituyó un primer avance del movimiento mapuche institucionalista al amparo de las primeras organizaciones modernas del movimiento luego de la ocupación de La Araucanía: la Sociedad Caupolicán Defensora de la Araucanía (1910-1938), bien ligada al Partido Democrático Liberal y al Partido Demócrata, y la Federación Araucana (19221948?), aliada a la Federación Obrera de Chila y al Partido Comunista. Para ese entonces surgió la convicción dentro del movimiento mapuche de que ya que no se podía hacer una defensa bélica del wallmapu, pero sí se podía hacer una defensa política usando los instrumentos del derecho que les correspondía al ser obligados a constituirse como ciudadanos chilenos y argentinos. Necesidad imperiosa ya que se encontraban en situación de indefensión frente a la ley (Kallfvkvra, 9 de septiembre 2014). A partir de aquellas primeras organizaciones, el movimiento recorrió un camino muy difícil de negociación y alianzas con la clase política que sería muy extenso narrar. Basta con señalar que mientras parecía que las comunidades terminarían desapareciendo por completo, y con ello el propio 
mapuche, las demandas de las organizaciones que fueron surgiendo luego de las dos primeras alcanzaron escaza voz dentro de la clase política ${ }^{19}$. No obstante, el movimiento logró con relativo éxito ocupar cargos en el Parlamento y en algunos municipios. La historia de los parlamentarios mapuche no se ha escrito todavía y por lo que conocemos no deja de ser interesante, sus demandas y discursos reflejan con mucha claridad aquel movimiento que intentará, una y otra vez, con incansable persistencia, reivindicar la etnia. Hubo siete diputados mapuche antes del golpe de Estado ${ }^{20}$. A la llegada de la Reforma Agraria, el movimiento mapuche institucionalista renovará sus fuerzas cunado logra unirse al movimiento campesino sindicalizado y así conformar el movimiento mapuche-campesino institucionalista.

A lo largo del siglo XX fueron creadas tres instituciones estatales con objeto de prestar atención e intentar "solucionar" el problema mapuche: los Juzgados de Indios (creados en 1931) ${ }^{21}$, la Dirección de Asuntos Indígenas (DASIN, 1953) ${ }^{22}$ y la Ley Indígena 14.511

\footnotetext{
${ }^{19}$ Sobre este tema ver un par autores que hemos citando: Foerster y Montecino (1988) y Caniuqueo (2006).

${ }^{20}$ El primer diputado fue Francisco Melivilu por el Partido Demócrata, elegido 1924; luego Manuel Manquilef, por el Partido Liberal en 1926; en 1933 Arturo Huenchullán, por el Partido Demócrata; en 1945, 1949 y 1968, es elegido Venancio Coñuepan (quien en 1938 fundó la Corporación Araucana), por el Partido Conservador; en 1953, José Cayupi y Esteban Romero, por el Partido Nacional Cristiano y apoyados por la Corporación Araucana; y en 1973, Rosendo Huenumán, por el Partido Comunista. Sería muy extenso detenernos en este punto, pero, vale la pena hacer un paréntesis para revisar brevemente, a modo de ilustración, la biografía política de Rosendo Huenumán, el último diputado mapuche de la lista. Rosendo Huenumán García es parte de una historia del pueblo mapuche poco explorada. Nació en Hueñalihuén, comuna de Puerto Saavedra, en 1935. Comenzó a trabajar siendo niño. A los 12 años llegó a Temuco como mozo de la familia de un empresario local. Cursó estudios primarios en una escuela nocturna, para luego emigrar a Concepción con el sueño de convertirse en profesor. Trabajando en Lota como minero del carbón conoció la "explotación del hombre por el hombre". De regreso a su hogar, su comunidad natal fue una de las primeras en iniciar un proceso de recuperación de tierras, previo a la Reforma Agraria. Fueron duramente reprimidos por el gobierno de Jorge Alessandri; pese a ello, "mostraron un camino a seguir" (Cayuqueo 2008). Bajo el gobierno de Frei, participó activamente en la sindicalización campesina, transformándose en un respetado líder mapuche. Durante la Unidad Popular, fue presidente de la Federación Campesina Luis Emilio Recabarren y dirigente de la Federación Campesina e Indígena Ranquil. En 1973, aliado al Partido Comunista, fue elegido diputado por Cautín con la primera mayoría y participó en la Comisión de Agricultura y Colonización de la Cámara de Diputados hasta la disolución del Parlamento por la dictadura. El diputado "había llegado al Parlamento a representar las demandas históricas de su pueblo. Su atrevimiento lo pagó con persecución y largos años de exilio, salvando incluso de la muerte cuando los militares -equivocadamenteasesinaron a otro mapuche con su mismo apellido". Huenumán no puede ser identificado como un militante "tradicional" del PC. Como señala en una entrevista que le realiza Cayuqueo, su unión con el PC representó más bien una alianza política que un compromiso ideológico. Sus metas estaban más allá de aquellas que había planteado el Partido para la Reforma Agraria. Tan indigenista como comprometido con las clases populares, entendía que la Reforma Agraria era tan necesaria para el campesino como para la reivindicación del pueblo mapuche. Desde su punto de vista, ambas cosas eran perfectamente compatibles (Cayuqueo 2008).

${ }^{21}$ Dichos Juzgados verán las causas de usurpación de tierras, las solicitudes de radicación, autorizarán la división de las comunidades y la venta de esas tierras. En estas divisiones se encuentra el origen de parte importante de los conflictos de tierras que perduran hasta hoy en día. La Comisión Verdad Histórica y Nuevo Trato, indica que estos Juzgados anularon los Títulos de Merced, facilitaron la división de las tierras y su posesión a los particulares no indígenas. Además, generalmente no atendieron a favor de los indígenas las causas reivindicatorias (CVHNT 2003a: 49-50).
} 
$(1961)^{23}$. Como ninguna de estas instituciones había traído una mejoría a las comunidades y al problema de sus tierras, fueron blancos de ataque por parte del movimiento mapuche en general y foco de fuerte discusión política en su interior cuando en el gobierno DC se discute la profundización de la Reforma Agraria. Sin embargo, el Programa de Gobierno marginó de la discusión sobre Reforma Agraria al tema mapuche, lo que incluyendo también a dichas instituciones, ya que la DC y la clase política tradicional consideraron al mapuche igual que al resto de los campesinos pobres, sin mostrar interés por su problemática histórica o su identidad. Incluso los partidos de la izquierda tradicional sufrían de bastante miopía respecto a las demandas del sector. Por lo general, los socialistas de esos años "creían que se arreglarían los asuntos indígenas dividiendo las comunidades y formando cooperativas en el campo. Los comunistas no plantearon la división de las reservas, pero consideraban la cuestión mapuche como un asunto campesino" (Bengoa, 2002: 138). El objetivo de la clase política tradicional, fue intentar integrar al mapuche al campesinado chileno con el programa de Reforma Agraria, en ese contexto la cuestión mapuche fue tematizada dentro del problema general del minifundio (escasez de tierra, de crédito, de tecnología, de comercialización, etc.) (Samaniego y Ruiz 2007: 267-324, Foerster y Montecino1988: 285).

Cuando comienza a ser más notoria esa discusión, entre fines de la década de los 50 y comienzos de los 60, la Corporación Araucana (1938-1968), fundada bajo el respaldo del Partido Conservador y principal organización del movimiento mapuche en la década de los 50, sufre un quiebre institucional que la llevará a su desaparición. Siendo Venancio Coñoepan presidente de la Corporación, el quiebre se produjo, principalmente, debido a su apoyo a los candidatos conservadores, apoyo que al entrar los 60 no sería compartido por el resto de sus líderes, a ello se sumaría, en última instancia, la muerte de Coñoepan en 1967 (Foerster y Montecino1988: 286) ${ }^{24}$. Con este quiebre la Corporación comienza a

\footnotetext{
${ }^{22}$ La Dirección tenía por objeto modernizar la producción de las tierras comunitarias. Con ella se crea también un modesto Programa de Becas para Estudiantes Indígenas y un sistema, también modesto, de créditos financiado por el Banco del Estado, la Caja Central de Indígenas.

${ }^{23}$ La Ley va tener vigencia durante toda la década del sesenta. Estrictamente integracionista, tratará de implementar la división de las comunidades, a la vez que intentará resolver la necesidad de crear unidades económicas viables en el campo.

${ }^{24}$ Sostenemos que dicho apoyo obedecía a que la Corporación creyó que esta sería la única manera de dar solución a algunas de sus demandas, entre ellas, poner fin la división de las tierras comunitarias. Primero se unió a Carlos Ibáñez del Campo apoyándolo desde su candidatura y luego hizo lo mismo con Jorge Alessandri Rodríguez (Bengoa 2002: 95-116; Foerster y Montecino 1988: 291-296). Esta alianza, que no debe entenderse necesariamente como "derechista" (como algunos sostienen), fue más bien una estrategia política que permitió al movimiento alcanzar algunas conquistas, como la creación del DASIN y los primeros programas de becas y créditos para indígenas. Estas políticas fueron instituidas gracias a los esfuerzos del diputado mapuche e histórico presidente de la Corporación Araucana Venancio Coñuepán, del Partido Conservador. En su calidad de político influyente, Coñuepán ejerció una constante presión para que se atendieran las demandas mapuche, pues creyó que la mejor manera de alcanzar algunas reformas tendientes a superar la situación mapuche, era cambiando el Estado "desde dentro". La Corporación Araucana siempre resistió la división de las comunidades, pese a su alianza con la derecha (Bengoa 2002: 114). El propio Coñuepan, dice Bengoa, "afirmaba que para lograr las conquistas araucanas había que aliarse con los que tenían el poder en forma directa. Entendía así la alianza con la derecha. Otros dirigentes señalan que era sólo instrumental la relación con el Partido Conservador, o con el Agrario Laborista o con el ibañismo, después. Que siempre ellos fueron
} 
disgregarse en un grupo diverso de nuevas organizaciones, todas vinculadas a los partidos políticos tradicionales de izquierda y derecha ${ }^{25}$. También en medio de la discusión sobre las reformas del Estado, junto a estas nuevas organizaciones aparecen otras que no tenían vínculos con la Corporación Araucana. En ese contexto surgen la Sociedad Lautaro, en 1958, con cierta afinidad y lazos con la DC; la Federación Nacional Campesina e Indígena de Chile, en 1961, con fuertes lazos con la Central Unitaria de Trabajadores, con el movimiento campesino sindicalizado y el Frente de Acción Popular (FRAP); el Movimiento Indígena de Chile, en 1965, más bien dependiente del Partido Democrático Nacional (de derecha). Al año siguiente se constituyen la Federación Araucana El Toqui y la Federación Universitaria Indígena (1966), unidas a los partidos de centro y orientadas a convocar a la mayor parte del espectro político y de las organizaciones mapuchecampesinas que les fue posible, lo mismo hizo la Confederación de Sociedades Mapuches, nacida en 1969. Ese último año también surge la Federación de Trabajadores y Agricultores Mapuches Luís Emilio Recabarren, con fuertes lazos con el PC. A demás del hecho de que en ellas solían participar miembros no mapuche, todas se unían institucionalmente (de acuerdo a la planificación estatal), a través de las federaciones y confederaciones sindicales y a través de los partidos, al movimiento campesino no indígena (Foerster y Montecino 285-362). Así, junto con ser mapuche, estas organizaciones también formaban parte del movimiento campesino no indígena, constituyendo una suerte de identidad mapuchecampesina (Saavedra 2002: 97-99).

Entre estas organizaciones se desarrolló una fuerte disputa por la hegemonía de sus proyectos históricos. Sin embargo, esta disputa se encontraba bastante influenciada por la competencia político-partidista e ideológica respecto a distintos modelos de transformación capitalista. Lo interesante, es que este tipo de organizaciones buscan instalar en el debate que abre la Reforma Agraria, la transformación del Estado en favor de la etnia y, a través de la instrumentalización de los partidos y del movimiento social (con quien constituyen alianza), alcanzar conquistas de gran significado para la reivindicación del pueblo y del territorio mapuche. Esto implicaba modificar por completo la legislación indígena vigente y, con ello, las relaciones de dominación Estado-pueblo mapuche que habían cruzado todo el siglo XX a partir de la Pacificación de la Araucanía. Con este objeto pusieron su confianza en las posibilidades que abrió la política institucionalizada con las reformas democráticas que partieron el año 1958 (ya mencionadas) y lograron construir un diálogo ideológico fecundo entre las comunidades, el movimiento campesino, los partidos políticos y el Estado (Foerster y Montecino 1988: 285-358). Por esta razón, no podemos ubicar a estas instituciones ni dentro ni fuera de las comunidades o de los partidos políticos, ya que se organizaron como intermediarias, permitiendo a las comunidades, a través de los partidos y junto a la fuerza del movimiento social, construir puentes jurídicamente válidos

a las elecciones como Corporación Araucana" (Bengoa 2002: 113). Sobre esta discusión ver también: Hernández 2003: 241-242.

${ }^{25}$ Esta atomización se aprecia en la disgregación de las fuerzas indígenas para enfrentar las elecciones de regidores, diputados y senadores. "Por ejemplo, en 1963 se presentaron más de 40 candidato mapuche, de todas las tendencias políticas, para ocupar cargos en los municipios. Con ello, el divisionismo se asentaba plenamente en el mundo indígena (cuestión que evitó con éxito la Corporación Araucana en las décadas de 1940 y 1950)" (Foerster y Montecino1988: 286). 
ante el Estado. Esto sería, a nuestro juicio, en definitiva, la clave y razón de ser de la alianza mapuche con el movimiento campesino institucionalista.

Las demandas del movimiento institucionalista cruzaban, a simple vista, con bastante familiaridad a las distintas organizaciones, pero, como vemos, éstas no coincidían en sus marcos ideológicos, en sus compromisos partidistas, ni en la forma de entender el territorio y la historia mapuche, pues algunas organizaciones buscaban cambios más profundos e indigenistas que otras. El punto más controversial sería la división de las tierras comunitarias, ya que algunas, como el Movimiento Indígena de Chile, ligado al Partido Democrático Nacional, estaban a favor de esta política; otras, en cambio, señalaban que la supervivencia del mundo mapuche se encontraba en la vida al interior de las comunidades (Ibíd.: 317-322). Las organizaciones no sólo asumirán la defensa de la Reforma Agraria, a la cual le intentarán imprimir un carácter especial, tratando que se incluya la entrega de tierras a las comunidades o la restitución de aquellas que habían sido usurpadas de los Títulos de Merced, sino que también, en segundo lugar, demandarán educación para los mapuche, entrega de créditos y vivienda, entre otras demandas tanto culturales como destinadas a la superación de la pobreza (Ibíd.: 288-232).

Como era de esperar, las organizaciones comprometidas con los partidos de izquierda fueron más radicales que aquellas unidas al centro o derecha. La Federación de Trabajadores Agrícolas y Mapuches Luis Emilio Recabarren y la Federación Nacional Campesina e Indígena de Chile, ligadas al FRAP y a la CUT, fueron las únicas que brindaron apoyo directo a la tomas de fundos (Ibíd.: 297-317). En cambio otras, como la Federación Universitaria Indígena, de carácter multipartidista y más ligada al centro, solidarizó con las tomas y con los mapuche detenidos en ellas, pero no brindó otro tipo de apoyo (Ibíd.: 323-228).

Por otro lado, es interesante también analizar el giro programático que dio la Corporación Araucana antes de desaparecer, pues intentó ponerse a tono con las demandas y posibilidades de los nuevos tiempos. A pesar de que Coñoepan mantuvo su apoyo a los candidatos conservadores, apenas la situación política se torna más favorable para el movimiento mapuche, la Corporación Araucana dará un giro programático apoyando la Reforma Agraria a pesar de la molestia de su mayor aliado político, el Partido Conservador (partido de los terratenientes). Bengoa señala que en un discurso, Coñuepán mostró claramente "su apoyo a la entrega de tierras a los campesinos; sus camaradas terratenientes obviamente lo miraban con curiosidad y no con demasiada simpatía" (2002: 141). También la Corporación realizó algunos actos públicos demandando que la Reforma Agraria entregara tierras a los mapuche (Foerster y Montecino 1988: 295). Como parte de este giro programático, lo que quedaba de la desintegrada Corporación colaboró con la formación de la Confederación de Sociedades Mapuches en 1969, compuesta por unas 45 organizaciones, casi todas ellas de centro e izquierda (Ibíd.: 296-351). Aunque en esos momentos estaba a punto de disolverse, en otro tiempo esta alianza no hubiera sido posible.

También resulta interesante el cambio de estrategia que adopta la Federación Nacional Campesina e Indígena de Chile, pues nos indica hasta dónde este tipo de organizaciones estaban dispuestas a seguir los "marcos legales" y evitar que la situación se les "escapara de las manos". La Federación participó activamente en tomas de fundos y movimientos de recuperaciones de tierras mapuche, desde 1961 a 1966, y en abril de 1964 lideró el 
compromiso que firmó el movimiento mapuche-campesino institucionalista en el Cerro Nielol con el entonces candidato a la presidencia, Salvador Allende, para redactar una nueva Ley Indígena (Foerster y Montecino 1988: 297-305; Samaniego y Ruiz 2007: 272281). A pesar de su historia de radicalización, cuando las tomas se vuelven habituales en la Araucanía, a partir de 1967, la Federación emprende una retirada a la zona central, para brindar a los mapuche un apoyo únicamente moral por medio de comunicados (Foerster y Montecino 1988: 297-314). Es posible que en ese cambio de estrategia haya influido la política de Allende, la vía constitucional. Acertadamente Foerster y Montecino señalan, que “el 'legalismo' de las organizaciones mapuche y su excesiva confianza en las autoridades nacionales les impidió canalizar las tomas y corrida de cerco" (Ibíd.: 297).

Desde la candidatura presidencial de 1964 hasta poco antes del golpe de Estado, el movimiento mapuche institucionalista, con apoyo del movimiento campesino, organizarán grandes "congresos nacionales mapuche", destinados a firmar acuerdos con la clase política para alcanzar los mayores logros posibles de las reformas del Estado. Estos acuerdos terminaron por simplificar las demandas en la única forma de canalización posible bajo la matriz clásica del Estado Fordista: a través de los partidos.

El primero de estos compromisos fue firmado por la Federación Nacional Campesina e Indígena de Chile, en un acuerdo con Allende en 1964 en cerro Nielol. El acuerdo contemplaba, como señalamos, la dictación de una nueva legislación indígena. Se estipuló que el nuevo cuerpo legal debía hacerse cargo de demandas culturales y territoriales. Sería el primer acuerdo histórico de este tipo. Fue escrito en el siguiente orden: la nueva Ley Indígena permitiría la libertad religiosa, incluyendo la práctica voluntaria de ritos ancestrales. En educación, ampliaría la cobertura básica dentro de las comunidades, crearía un currículum especial que incluiría la transmisión del mapuzungun, se crearían escuelas y liceos técnicos, se ampliarían las becas en distintos niveles, entre otros. Respecto a la propiedad de la tierra contempló, entre otros, la "restitución y remensuramiento de todos los fundos colindantes con comunidades o propietarios indígenas, para saber a ciencia cierta las hectáreas usurpadas y la vuelta inmediata a sus dueños" y la participación mapuche en "un porcentaje considerable en la Reforma Agraria". Por otro lado, la ley buscaría satisfacer las demandas de salud, vivienda y desarrollo rural, como la creación de un Banco Araucano de Desarrollo Agropecuario y Reforestación y la reorientación completa del DAIN, como su vinculación con distintos ministerios y su control por parte de mapuche. Por su lado, los dirigentes mapuche a nombre de las comunidades, se comprometieron en apoyar la candidatura de Allende y defender al "Gobierno Popular" (Foerster y Montecino 1988: 297-305; Samaniego y Ruiz 2007: 272-281).

Luego de ese primer compromiso, en diversas oportunidades las organizaciones invitaron a las autoridades a tratar los problemas mapuche, en especial aquellos relacionados con la Reforma Agraria. A fines de su gobierno Eduardo Frei comenzó a discutir con las organizaciones la reforma a la Ley Indígena 14.511, pero no logró resultados $^{26}$. En mayo de 1968, el diputado Juan Tuma en representación del Movimiento

\footnotetext{
${ }^{26}$ En enero de 1969 se reunió el Ministro de Tierras y Colonización con 200 dirigentes mapuche en el Teatro Municipal de Temuco, con objeto de tratar la reforma a la Ley Indígena (El Diario Austral, 18 de enero, 1969: 8). La reunión derivó en la formación del Comité Mapuche. El Comité quedo compuesto por un grupo de mapuche encargados de evaluar la propuesta de ley, para entregar la opinión del sector mapuche al
} 
Indígena de Chile (que él ayudó a formar), presentó un proyecto de ley de 14 páginas que introducía modificaciones a la Ley 14.511, con objeto de "agilizar el procedimiento de división", buscaba la restitución de tierras indígenas y regulaba la defensa de las mismas por parte de los organismos competentes (El Diario Austral, 15 de julio, 1968: 9; Foerster y Montecino 1988: 319-321). A pesar que el Movimiento Indígena de Chile encontró el apoyo del FRAP, de la CUT y de la Federación Campesina e Indígena, el proyecto de ley no logró concretarse (Foerster y Montecino 1988: 319-321). Por su parte, la Confederación de Sociedades Mapuches, se opuso al proyecto del senador Tuma, entre otros, porque sostenía que insistir en la división de las comunidades era terminar liquidándolas (Ibíd.: 328). Con estas disputas y el protagonismo que intentaban alcanzar las organizaciones en cada encuentro, quedaba claro el divisionismo al interior del movimiento.

Una vez iniciado el gobierno de la UP, comienza una política destinada a resolver la demanda de tierras mapuche. La tarea era difícil y compleja, ya que la Ley Indígena que operaba hasta ese momento no consideraba la restitución de tierras usurpadas y, por otro lado, las organizaciones mapuche-campesinas de izquierda no afiliadas a la UP buscaban transformaciones por la vía radicalizada, lo que tensionó en extremo un ambiente social que ya se venía desestructurado. En enero de 1971 se realiza el Segundo Congreso Nacional Mapuche. El principal diagnóstico que motivó la actividad, fue compartido por la UP y por el movimiento: que la Reforma Agraria de Frei era insuficiente para alcanzar transformaciones más profundas y satisfacer las demandas del sector. Allende pretendía elaborar una nueva Ley Indígena para dar cumplimiento a sus promesas de campaña, al acuerdo firmado en $1964^{27}$ y responder a las movilizaciones en el sur. El evento fue organizado por la Confederación Nacional Mapuche, quien discutió intensamente el Proyecto de Ley Indígena para entregar las observaciones finales a la UP. En ese entonces, la Confederación estaba compuesta por unas 45 asociaciones mapuche, entre ellas, la Corporación Araucana, Federación Universitaria Indígena, Moderna Araucanía, Unión Araucana y la Federación Campesina e Indígena Luis Emilio Recabarren (Foerster y Montecino 1988: 331).

Las diferencias entre el proyecto original y la ley definitiva fueron menores. El gran mérito de la nueva Ley Indígena 17.729, fue que por primera vez en la historia republicana se disponía de medios jurídicos efectivos para la restitución de las tierras indígenas usurpadas, y que dichos medios habían sido discutidos por parte importante de las propias comunidades afectadas. Esta legislación se constituyó así en el máximo logro alcanzado en la historia del movimiento mapuche (CVHNT 2003a: 410). Ella intentaba frenar el proceso

gobierno (El Diario Austral, 16 de febrero, 1969: 9). En estas actividades participó activamente la Confederación de Sociedades Mapuches, quien se encontraba bien ligada a los partidos y organizaciones mapuche de izquierda (Ibíd.) Sobre este proceso, ver uno de los textos que hemos venido citando: Correa, Molina y Yáñez (2005), La Reforma Agraria y las tierras mapuches. Chile 1962-1975, "La inoperancia de los Juzgados de Indios y la discusión de una Nueva Ley Indígena”, pp. 121-126.

${ }^{27}$ El Programa de Gobierno de la Unidad Popular planteó la profundización de la Reforma Agraria y fue el único que en la elección presidencial de 1970, prometió hacerse cargo de la problemática mapuche, pues se comprometió a "la defensa de la integridad y ampliación y asegurar la dirección democrática de las comunidades indígenas, amenazadas por la usurpación, y que al pueblo mapuche y demás indígenas se les asegure tierras suficientes y asistencia técnica y crediticia apropiadas" (Unidad Popular: 23, citado en Correa, Molina y Yáñez 2005: 137). 
de división de las comunidades y establecer la posibilidad de restituir las tierras a los indígenas, utilizando para ello el mecanismo de la expropiación contemplado en la Ley de Reforma Agraria. Será la primera vez que un cuerpo legal se refiera y defina a los indígenas independientemente de sus tierras.

Sus objetivos fueron: 1) la transformación del sistema de tenencia y explotación individual por fórmulas cooperativas o comunitarias perfectamente organizadas como unidades de producción; 2) el impulso sistemático y enérgico al desarrollo de los grupos autóctonos, a través de medidas económicas, sociales, educativas, jurídicas y otras que los integraran sin asimilarlos a las actividades nacionales; 3) la creación de un instrumento ágil y funcional, que permitiera al Estado planificar y llevar a cabo una política integral de desarrollo; 4) esta ley contempló la creación de una Judicatura especial para indígenas: Reestructurar la administración de justicia indígena; 5) establecer un procedimiento verbal y rápido, en que se entregara una participación activa a los comuneros Indígenas afectados en la Litis; y 6) establecer el derecho a la defensa jurídica, la que se manifestaría en la asistencia y gratuidad legal (CVHNT 2003b: 45). Por último, esta ley también crea el Instituto de Desarrollo Indígena, organismo destinado a centralizar las políticas del Estado dirigidas a la sociedad indígena. Su creación obedece a la necesidad de "promover el desarrollo de los indígenas, procurar la integración de los indígenas a la comunidad nacional, considerando su idiosincrasia y respetando sus costumbres" (Stavenhagen 1988: 68, citado en Ibíd.). En él se contemplaron planes de desarrollo agropecuario, becas de estudio y hogares estudiantiles. La vigencia de esta ley fue de corto aliento. A los seis meses de haberse promulgado sobrevino trágicamente el golpe de Estado.

\section{Desde abajo y desde fuera de la política tradicional: el movimiento mapuche- campesino no institucionalista}

En la formación del movimiento mapuche-campesino no institucionalista convergieron de manera paulatina una izquierda revolucionaria, que en términos ideológicos se ubicaría fuera de la DC y de UP, y las comunidades indígenas que adoptan la vía insurreccional. Dicha convergencia se habría producido a partir de un profundo diálogo al interior de las comunidades y también entre éstas y la izquierda revolucionaria, en especial con el MIR (Saavedra 2002; Alfaro 2011) ${ }^{28}$, para así lograr constituir una fuerte alianza.

Las movilizaciones de este sector, tomas, recuperaciones de tierra y otras, se desarrollaron en sucesivas oleadas con una fuerte tendencia hacia una escalada de violencia. Las autoridades de los gobiernos de Frei y Allende se sintieron presionadas a buscar mecanismos que permitieran administrar el conflicto, intentando encausarlo por la

\footnotetext{
${ }^{28}$ Los autores citados dejan muy claro este punto, así también los testimonios orales (Carvajal y Peralta 2006). Señalan que el MCR surge a partir de un encuentro entre el MIR y algunas comunidades de Cautín, entre 1968 y 1969. Pronto extiende por diversas zonas del sur, la mayoría de sus líderes, como Alejandro Manque, Dirigente Nacional, fueron mapuche. Este encuentro habría sido motivado por la propia pobreza y la memoria histórica de la usurpación, más que por cuestiones ideológicas que los mapuche, al contrario de los miristas, poco conocían. Como señalamos, esto en ninguna manera convierte a los mapuche en "masa de maniobra" del MIR o de la UP, como sostiene cierto discurso de la derecha (Mallon 2004: 89-132).
} 
vía institucional. Estos esfuerzos fueron poco fructíferos, a pesar que el primero de ambos gobiernos hizo uso de la violencia de Estado en más de una oportunidad (El Diario Austral, 11 de julio, 1970: 7; Correa, Molina y Yáñez 2005: 118). Los terratenientes, por su lado, exigieron la acción policial y también respondieron a las movilizaciones con violencia, pues desenfundaron sus armas y organizaron "comités de retomas" para tomar la justicia por sus propias manos (Linfati 2003; Mallon 2004: 94-104).

Revisemos los hechos. Desde comienzos de la década del 60 la prensa venía informando sobres tomas de fundos por parte de mapuche (Revista Ercilla, 24 de diciembre, 1962; El Siglo, diciembre, 1963), lo que eran desalojados por Carabineros con armas de fuego. En uno de estos episodios muere, en mayo de 1963, una comunera en Cañete, María Silva Huenulao (El Siglo, 28 de mayo, 1963: 1). Como dijimos, en este primer momento tuvo activa participación la Federación Nacional Campesina e Indígena de Chile. De esta manera, la movilización se instalaba en la vía de los hechos concretos para la recuperación de tierras ocupadas "ilegalmente" por individuos no mapuche.

La situación se volverá aún más aguda pocos años después. Correa, Molina y Yáñez señalan que "las reivindicaciones de tierras por parte de comunidades mapuches se hacen sentir con más fuerza tan pronto se promulga la Ley de Reforma Agraria 16.640" (Correa, Molina y Yáñez 2005: 107). Recién dictada la Ley, la prensa local y nacional, sobre todos El Siglo, comienza a informar una cantidad significativa de tensiones en la zona mapuche. Las comunidades esperaban su aprobación para exigir respuesta a sus demandas históricas (Correa, Molina y Yáñez 2005: 107-108). A partir de esa fecha, irán apareciendo nuevas organizaciones del movimiento mapuche-campesino no institucionalista. La Comisión Verdad Histórica y Nuevo Trato, señala que los sectores movilizados defenderían dos argumentos que explicarían dichas acciones: "El primer argumento se relaciona con el contexto reivindicatorio propio de la reforma agraria, que consiste en detectar y expropiar las tierras abandonadas o subutilizadas; el segundo argumento gira en torno a las tierras que tienen carácter de usurpadas por parte de los terratenientes" (CVHNT 2003a: 405).

Entre 1967 y 1968 un grupo de comunidades mapuche se unen a la Confederación Nacional Campesina e Indígena de la Provincia de Malleco para iniciar un importante proceso de "recuperación de tierras" en Ercilla y Lumaco que comprometió, al menos, unos seis fundos (El Siglo, 23 de mayo, 1968: 7). El empleo de la fuerza policial, que en más de una ocasión provocó algunos heridos, comenzó a ser cada vez más habitual durante el gobierno de Frei y éste decide declarar el departamento de Collipulli como Zona de Emergencia, lo que implicaría la presencia permanente de Fuerzas Especiales de Carabineros, gracias a la aplicación del Estado de Excepción Constitucional (El Diario Austral, 11 de julio, 1970: 7; Correa, Molina y Yáñez 2005: 118). A pesar de la represión, por primera vez las comunidades movilizadas logran la expropiación de algunas tierras ( $E l$ Diario Austral, 13 de abril, 1969: 3; 8 de agosto, 1969: 8).

Estos hechos también favorecieron la formación de la Cooperativa Lautaro de Lumaco, quien se uniría a la Confederación Campesina e Indígena Ranquil para cumplir, junto a otras organizaciones, un rol protagónico dentro de los sectores mapuche-campesinos movilizados en Malleco y Cautín (Correa, Molina y Yáñez 2005: 108-118). Pronto las movilizaciones se extendieron desde la parte norte de la provincia de Malleco a Lautaro y Nueva Imperial para seguir avanzar a otras zonas. En el mes de septiembre de 1968 en la 
comuna de Lautaro, la presión estatal se hace sentir contra dirigentes de comunidades mapuche adscritas a la Confederación Campesina e Indígena Ranquil. Emblemático es el caso de la familia Catalán Lincoleo, del sector Huerquerco, ubicado a 12 kilómetros de Lautaro, que demandaban tierras usurpadas por agricultores aledaños. "Las fuerzas policiales allanaron la vivienda de la familia Catalán Lincoleo, hicieron uso ilegítimo de la fuerza golpeando a menores y tomaron presos a miembros de las familias Catalán y Millalen, quienes fueron acusados de abigeato, sin que existieran pruebas que acreditaran su participación en los hechos que se le imputaban" (Ibíd.: 120).

Desde fines del gobierno Frei hasta el golpe de Estado, el naciente MCR impulsa en la provincia de Cautín un proceso de recuperación de tierras conocido como "corrida de cercos". Éstas eran denominadas por sus promotores como "acciones directas", destinadas a acelerar las transformaciones revolucionarias y recuperar las tierras usurpadas de los Títulos de Merced por parte de los terratenientes. Con ello se intentaba hacer justicia frente a las reclamaciones de tierras mapuche. En forma casi paralela a las corridas de cercos, el MCR impulsó en las comunidades otro tipo de acción: las "ocupaciones de fundos", ya no para restablecer tierras usurpadas de los Títulos de Merced, sino para recuperar tierras ancestrales, no reconocidas en dichos títulos y que se encontraban dentro de los predios particulares colindantes. Junto al MCR, otras organizaciones también participaban de estas acciones $^{29}$. Este nuevo accionar surge a fines del período demócrata cristiano, en las comunas de Lautaro y Loncoche (Ibíd.: 128). Durante 1969, las movilizaciones se extienden por gran parte de la provincia de Malleco y adquieren un carácter masivo y "revolucionario". Aumentan las "corridas de cercos" y "ocupaciones de fundos" a cargo del MCR (Carvajal y Peralta 2006; Bengoa 2002: 117-148).

Frente a esta situación, el gobierno envió a la Región, en noviembre de 1969, al Ministro de Tierras y Colonización para resolver cada caso. Se estudió cada uno en particular para dar curso a la Ley de Reforma Agraria. Con ello se daba a entender que se desconocían las reivindicaciones mapuche y los Títulos de Merced. Ello sería confirmado en agosto de 1970 por el Intendente de Cautín, Silvius Pavissich, en declaraciones a la prensa, ya que sostuvo la imposibilidad de dar respuesta a tales reclamaciones (El Diario Austral, 12 de agosto, 1970: 1; Correa, Molina y Yáñez 2005: 126-131).

En síntesis, durante el gobierno de Eduardo Frei Montalva, por lo que se puede constatar en información que entrega El Diario Austral y El Siglo, las tomas en algunos casos eran respondidas mediante una política dual: represión policial y entrega de unas cuantas tierras a cooperativas y asentamientos campesinos; mientras que en otros casos, el Estado sólo respondió con represión (El Diario Austral, 31 de agosto, 1969: 11; 15 de

\footnotetext{
29 Bengoa (2002) cita el siguiente comunicado de prensa "La Asociación de Pequeños Agricultores de Loncoche que agrupa a más de 1.800 campesinos organizados en 37 Comités, quiere comunicar a todos sus asociados que hemos acompañado a las comunidades mapuches de Pérez Molfinqueo y Francisco Briseño en la acción de corridas de cerco para recuperación de las tierras usurpadas". Agregaba más adelante que "esta acción se ha realizado por la tramitación de más de 30 años por parte de los Tribunales de Justicia y para recuperar más de 120 hectáreas de tierras que a pesar de pertenecerles según consta en Actas de la Comisión de Títulos de Merced a Indígenas de fecha 5 de mayo de 1913, se encontraba en manos de particulares. El principal usurpador de la tierra después de la entrega de los Títulos de Merced a las comunidades mapuches fue Elías Montecinos, quien arrebató la tierra violentamente en un hecho que resultó sangriento (p. 128).
} 
diciembre, 1969: 15; 20 de febrero, 1970: 11; 11 de julio, 1970: 7; El Siglo, 25 de septiembre, 1968: 5). La entrega de tierras fue favorecida gracias a la aplicación de la Ley 16.640, pues se entregaron únicamente cuando los fundos excedían las 80 has. de riego básico, condición exigida para la expropiación de las tierras restantes y se favorecieron a las comunidades organizadas en cooperativas (Toledo 2006: 30-38; Correa, Molina y Yáñez 2005: 131). En suma, durante la Reforma Agraria de Frei, fueron restituidas a las comunidades unas 20.595,8 has (Correa, Molina y Yáñez 2005: 131).

Las movilizaciones se acentúan aún más en el gobierno de la UP. En la zona de Lautaro y Galvarino las corridas de cerco se reiniciaron y pronto hechos similares se repitieron en Loncoche, Cunco y otras zonas (Correa, Molina y Yáñez 2005: 140; Mallon 2004: 89-132; CVHNT 2003a: 406). Para fines de 1970, apenas había asumido Allende, las tierras tomadas superaban las 100 mil has. y seguían avanzando hasta las cercanías de Valdivia en un clima extremadamente tenso. En febrero de 1971 se constituía en Cunco el segundo Consejo Comunal Campesino, formado por campesinos mapuche y winka pobres. El caso más avanzado, se decía, de cooperativismo que se había realizado en esa comuna (Bengoa, 2002: 151-152). El enfrentamiento de estos grupos con los propietarios organizados en "comités de retoma" provocaría más de una desgracia fatal (Bengoa 2002: 151; Correa, Molina y Yáñez 2005: 136-153; Linfati 2013; Mallon 2004: 94-104). Esta gran oleada de movilizaciones se conoce como Cautinazo (CVHNT 2003a: 406 y ss.).

Viendo las ocupaciones masivas de fundos, el gobierno de la UP hizo todos los esfuerzos para acelerar las expropiaciones y ampliar aún más los canales institucionales. Así, la política campesina del gobierno se expresó, en primer lugar, en una nueva iniciativa que buscaba la creación de organismos centrales del Poder Popular. Por ello, mediante el Decreto 214 se crean los Consejos Campesinos a nivel local y se constituye el Consejo Nacional Campesino, con el objeto de agilizar el desarrollo de la Reforma Agraria. Estas instancias " "legales', tendrían la responsabilidad de representar a los campesinos chilenos a través de sus organizaciones reconocidas a nivel nacional, entiéndase las confederaciones: 'Ranquil'; 'Triunfo Campesino'; 'Libertad'; 'Nacional de Cooperativas' y la 'de Asentamientos"' (Llanos 2009: 71). El 15 de enero de 1971, el Ministro Jacques Chonchol conformó en Temuco y por decreto, el Consejo Provincial Campesino, el cual pasaba a constituirse con dos representantes de las organizaciones recién señaladas. El presidente fue el democratacristiano Manuel Inzunza (Ibíd.).

Otra respuesta del gobierno al Cautinazo, se tradujo en el envío de un cuerpo amplio de representantes del Estado, encabezados por el Ministro de Agricultura Jacques Chonchol, a la ciudad de Temuco para resolver rápidamente la expropiación de los predios demandados. Así se ejecuta un Plan de Emergencia para Cautín, que comprendía una serie amplia de programas asistenciales $^{30}$. A raíz del Cautinazo en los meses de enero y febrero de 1971, se

\footnotetext{
${ }^{30}$ En dicho Plan se incluían medidas de activación económica destinadas a generar empleos, como el mejoramiento de caminos, construcción de bodegas para cereales, fábricas de cecinas y otras construcciones. En lo que se refiere al agro, se abrieron poderes compradores de madera para poner en marcha 50 aserraderos, y se implementó el plan de forestación de 4.800 hectáreas en convenio entre la Corporación de Reforestación y la Corporación de Reforma Agraria. Esta última actividad dará paso a la reforestación de numerosos asentamientos mapuches, formados en predios expropiados. Con esas medidas el gobierno de Salvador Allende deseaba enfrentar la situación deprimida de la región (Correa, Molina y Yáñez 2005: 144).
} 
restituyeron unas 13.416,2 has. a las comunidades mapuche de las tierras usurpadas (Correa, Molina y Yáñez 2005: 146-147). Este proceso también dio origen a la Comisión de Restitución de Tierras Usurpadas, dependiente del Instituto de Desarrollo Indígena. De esta forma las autoridades intentaban resolver el problema de la manera más efectiva y rápida posible, haciendo uso de los medios que entregaba la Ley de Reforma Agraria. Sin embargo, el gobierno estaba consciente que estos medios no eran suficientes para responder a las demandas indígenas, por ello de forma paralela se intentaba reformular la Ley Indígena. Por primera vez desde la Independencia, el Estado dejó su actitud atropelladora y tendió una mano amiga al mapuche (Salazar 2012: 123; CVHNT 2003a: 408).

Estos hechos marcaron un período que dejó en lo inmediato a lo menos tres resultados positivos para el movimiento mapuche: a) se logra una importante restitución de tierras; b) se produce un fortalecimiento organizacional del movimiento mapuche-campesino institucionalista gracias a la mediación de la Confederación Nacional Mapuche en la intervención estatal que vino a raíz del Cautinazo; y c) se logró agilizar la discusión del proyecto de Ley Indígena; la misma Confederación ejercerá una fuerte presión para cambiar la Ley 14.511, tan combatida por las comunidades porque perseguía su división (CVHNT 2003a: 409). Estas conquistas y la casi inexistente represión por parte las autoridades, fue interpretado por el movimiento mapuche-campesino como un escenario sociopolítico favorable a las reivindicaciones y pensó que podía "ir por más". Las movilizaciones se detuvieron momentáneamente para reaparecer en los meses siguientes.

La constitución del Poder Popular oficial, propiciado por Allende con los Consejos Campesinos, fue inmediatamente desafiada por sectores de base campesina en la provincia de Cautín. El 16 de enero de 1971, se crea en la comuna de Lautaro el primer Consejo Comunal Campesino nacido al alero del MIR, "desde las bases" (como se decía), sin esperar el reconocimiento legal o la firma de ministros. En los días posteriores se constituyeron consejos en otras comunas. La participación de campesinos mapuche era importante en estas organizaciones ${ }^{31}$.

Paralelamente se empiezan a desarrollar tareas de tipo militar, aunque bastante precarias. Estos eran los Grupos Político-Militares (GPM), una idea que venía de los mirista de Santiago. José Peralta (seudónimo de Gustavo Marín como militante del MIR, Secretario del Comité Regional en Malleco y Cautín entre 1970 y 1973) en uno de sus testimonios, indica que "había grupos que se enfrentaban en defensa personal, otros que realizaban escondites para la fabricación de armamento casero. Había una cierta compartimentación, clandestinización, pero no era realmente de calidad" (Peralta 2006: 81). Uno de los problemas que afectó su funcionamiento, fue que la poca fuerza con que contaban se debía dividir entre las tareas políticas y las militares, "organizando fuerzas más bien artesanales, preparando una revolución por venir" (Ibíd.).

\footnotetext{
${ }^{31}$ Señala José Peralta: "En Cautín empezamos a organizar los Consejos Comunales Campesinos pero en lugar de limitarnos a una reagrupación de sindicatos y cooperativas ya existentes, lanzamos la elección democrática, por debajo de los Consejos. Nos encontramos con la oposición de los comunistas, socialistas y democratacristianos porque controlaban burocráticamente los sindicatos. Los líderes del MCR ganaban las elecciones de los Consejos Comunales, pero los partidos de la UP empezaron a frenar ese proceso" (Peralta 2006: 81).
} 
A simple vista parecía que los esfuerzos históricos del gobierno (en medio de la resistencia de la oposición conservadora y de la izquierda más extrema) estaban dando resultados positivos según lo previsto en su Programa, pero, en realidad, la situación se estaba reconfigurando, tanto por parte de la oligarquía como por parte de los sectores revolucionarios fuera de la UP.

Pocos meses después de la puesta en marcha del Plan de Contingencia, nuevamente la Araucanía parecía un polvorín a punto de estallar. Militantes del Partido Comunista Revolucionario (facción política de inspiración maoísta), se organizaron para formar el Movimiento Revolucionario Ñetuain Mapu (Correa, Molina y Yáñez 2005: 149-153; Bengoa 2002: 151). Este se extendió rápidamente, abarcando Cunco, Freire, Nueva Imperial, Carahue y Puerto Saavedra, desde fines 1971 hasta el golpe de Estado (Steenland 1977: 114, citado en Correa, Molina y Yáñez 2005: 149). El Ñetuain Mapu vino a sumarse a las actividades del MCR, que había impulsado una nueva campaña de recuperación de tierras a mediados del mismo año. El movimiento fue de tal magnitud, que durante 1971 se registraron 1278 ocupaciones de tierra (Ibíd.: 148). El gobierno dobló sus esfuerzos, prefiriendo el diálogo con las comunidades en vez del envío de la fuerza pública (como había ocurrido durante el gobierno de Frei). En un acuerdo logró que el MCR devolviera algunos fundos, en tanto la CORA, por medio de la Comisión de Restitución de Tierras Usurpadas, se comprometía en estudiar la expropiación de los predios en el año próximo ${ }^{32}$. Como el Presidente desestimó el envío de la fuerza pública y privilegió el diálogo, las organizaciones patronales nuevamente actuaron, causando la muerte de dos mapuche y varios heridos (El Diario Austral, 2 de enero, 1972: 11; 3 de abril, 1973:7).

A fines de 1971, casi todas las tierras usurpadas a los mapuche de los Títulos de Merced ya habían sido devueltas. A pesar de ello, la voluntad de la UP por restituir tierras se hizo presente nuevamente con la firma del Convenio CORA-DASIN, cuyo objetivo era agilizar las expropiaciones a favor de comunidades mapuche (Órdenes 2014: 66). En medio de este contexto se aprobó la Nueva Ley Indígena, en agosto de 1972.

En suma, durante el proceso de Reforma Agraria llevado a cabo por la Unidad Popular (entre 1971 y el 11 de septiembre de 1973), se expropiaron en la Araucanía 574 predios, con una superficie de 636.288,3 has. Las tierras expropiadas a favor de comunidades mapuche o con participación mapuche fueron 137; unas 129.420,88 has. físicas; equivalentes a 11.280,04 has. de riego básico. Se restituyeron tierras consideradas usurpadas de los Títulos de Merced y también tierras reivindicadas como territorio ancestral. Éstas se hicieron casi en su totalidad en las comunas de Malleco y Cautín (Correa, Molina y Yáñez 2005: 214).

\footnotetext{
${ }^{32}$ Las tareas asumidas por la Comisión de Restitución de Tierras Usurpadas se relacionaban con la remensura de los Títulos de Merced, acción destinada a respetar la integridad del título. Para estos efectos la Comisión realizó numerosos peritajes durante todo el año 1971, en los terrenos ocupados por comunidades mapuches, a fin de verificar los fundamentos en virtud de los cuales éstas alegaban que el fundo particular les tenía tierras usurpadas (Correa, Molina y Yáñez 2005: 159). El gobierno focalizó el trabajo de la Comisión en las comunas que presentaban mayores conflictos de recuperación de tierras mapuche, Lautaro, Imperial y Loncoche, en Cautín, y en la comuna de Panguipulli, en la provincia de Valdivia. Otra comisión actuó en Temuco, y se formó una 'Comisión Móvil' para resolver los conflictos de tierra de las comunidades de Bío Bío, Arauco y Malleco, todos casos en los que se procedería a remensurar las tierras han sido usurpadas o sustraídas ilegalmente del patrimonio mapuche (Ibíd.: 159-160).
} 


\section{Reflexiones finales}

A fines de la década de 1930, las etites políticas y empresariales llegan al consenso de que el campesinado debía ser postergado de las conquistas obreras urbanas si se pretendía alcanzar el programa de industrialización que llevaba a delante el Frente Popular. Tras un acuerdo entre el espectro multipartidista, el gobierno del Frente Popular y la SNA, el campesinado en general debió pagar duramente los costos de la industrialización urbana, lo que se tradujo en su exclusión sociopolítica, el estancamiento de sus condiciones laborales y represión en contra de aquellos, mapuche y no mapuche, que intentaron sindicalizarse o movilizarse abiertamente.

A partir de 1958 y con notoriedad en el gobierno de Frei, la situación comenzará a cambiar para el campesinado chileno en general. Los primeros cambios de inclusión ciudadana que afectarían significativamente, entre otros, a los campesinos, fueron la nueva Ley de Reforma Electoral (que permitió el voto a los analfabetos y puso trabas al cohecho con la implementación de urnas secretas) y la derogación de la Ley de Defensa Permanente a la Democracia. Luego, en el marco del corpus legal que acompañaría la profundización de la Reforma Agraria, junto a una serie de programas asistenciales que intentaron modernizar el campo y estimularon la formación de cooperativas campesinas, en 1967 se dictan la Ley de Reforma Constitucional, que puso fin al derecho de protección constitucional a la propiedad privaba, la Ley de Sindicalización Campesina y al nueva Ley de Reforma Agraria. Estas reformas del Estado ampliaron la democracia ciudadana-electoral, afectando positivamente la inclusión, por primera vez, de parte considerable del campesinado en la vida política-ciudadana y en los procesos electorales, librándolos de las intervenciones patronales y dándoles la capacidad de constituir organización social. Además, tales reformas trajeron una ampliación en cuanto a la democratización de la propiedad privada, al permitir la distribución del latifundio entre el minifundio y los no propietarios. Con estos cambios se transforma el sistema de partidos en desmedro de la derecha y se desestabiliza el pacto de dominación que ayudó a sostener al Estado subsidiario, a costa de la exclusión ciudadana y de la propiedad de la tierra que tanto perjudicó al campesinado.

Con el gobierno de la Unidad Popular vino una segunda etapa de ampliación democrática, también tanto en lo que respecta a la democracia ciudadana como a la democratización de la propiedad privada, ya que se dicta una nueva Ley de Reforma Constitucional, que permitiría agilizar las expropiaciones, afectando también la propiedad urbana. Así mismo, aumentaron los programas asistenciales de Reforma Agraria, estimulando aún más la sindicalización campesina.

Junto a las trasformaciones del Estado, se produjeron cambios muy relevantes en el plano ideológico tras la Revolución Cubana, entre ellos, el surgimiento de la Nueva Izquierda Latinoamericana, la formación de tendencias de izquierda revolucionaria que causaron divisiones en los partidos de centro y de la izquierda tradicional y el estallido del movimiento universitario. 
Así, con la Reforma Agraria y los cambios en el plano ideológico, se fue constituyendo una Estructura de Oportunidades Políticas que creó el ambiente político y social propicio para el desarrollo de los movimientos campesino y mapuche y, además, para la constitución de la alianza entre ambos, que cristalizará en el estallido del movimiento mapuchecampesino. Aunque las historias, situación social y demandas específicas de ambos movimientos eran muy distintas, éstos se unirían como "clase campesina" en su interés común de repartir el latifundio. En esta alianza el movimiento mapuche-campesino capitalizó y agenció los recursos sociales y políticos que ofreció la fuerza social que movilizaba, por un lado, la nueva izquierda revolucionaria y, por otro, el propio Estado con la formación de sindicatos mapuche-campesinos al alero de los partidos.

Las organizaciones mapuche-campesinas que nacieron al amparo de los sindicaros, pasaron a constituir el ala institucionalista del movimiento, en tanto que el sector que surge entre las organizaciones mapuche y las organizaciones de la izquierda más revolucionaria (autoexcluida de los sindicatos), como el MIR, pasó a constituir el ala no institucionalista del movimiento mapuche-campesino. En este marco, por ejemplo, surge el MCR. Lo interesante, es que las organizaciones institucionalistas buscan instalar en el debate que abre la Reforma Agraria, la transformación del Estado a favor de sus demandas. Para el caso de los mapuche, estimaron útil y necesaria la instrumentalización de los partidos y del movimiento campesino no mapuche, a fin de alcanzar conquistas de gran envergadura para la reivindicación del su pueblo y territorio. Esto implicaba, modificar la estructura del Estado y el régimen de propiedad privada y, con ello, las relaciones de dominación Estadopueblo mapuche que habían cruzado la historia. Por esta razón, estas instituciones se movilizaron como agentes intermediarios, permitiendo a las comunidades mapuche, a través de los partidos y sindicatos, construir puentes jurídicamente válidos ante el Estado. Por su parte, el movimiento no institucionalista creyó oportuno buscar la forma de generar condiciones para avanzar hacia la creación de una sociedad socialista, conformada por mapuche y no mapuche. En este proyecto, fueron considerados como prescindibles, e incluso hostiles, los sindicatos y el sistema de partidos, ya que representaban organismos institucionales de la "democracia burguesa".

Por último, es pertinente preguntarnos hasta dónde la profundización democrática puede transformarse en la constitución de una EOP favorable al conflicto social, de tal manera que estallen las contradicciones sociales y exclusiones históricas que afectan a los sujetos, como fue el caso del movimiento mapuche-campesino. En la década del 70, distintos autores de diversas tendencias (Wolfe 1977; Pateman 1970; Habermas 1975; Offe 1972, Crozier et al. 1975), sostuvieron que la ampliación democrática dentro de estados liberales, abría un espacio suficiente para que estallen las contradicciones del modelo capitalista, provocando tensiones entre el capitalismo, el régimen democrático y los sectores excluidos de los avances de la modernidad ${ }^{33}$; en otras palabras, la democracia

\footnotetext{
33 Paradigmático resulta en este sentido el Informe de la Comisión Trilateral en cuanto al diagnóstico que realiza de los factores generadores de ingobernabilidad en las sociedades avanzadas (Crozier et al. 1975). Según los autores del Informe, uno de los mayores factores de ingobernabilidad lo constituye el aumento de las demandas y de la participación social y política experimentado en el siglo XX hasta la década de los 60 . Por tal motivo, proponen como vía alternativa la reducción de los mecanismos y canales democráticos que promueven la participación y la demanda social.
} 
permitiría el aumento de la inestabilidad social, haciendo que los regímenes democráticos sean difíciles de gobernar ${ }^{34}$. Más recientemente Salazar, siguiendo a Samuel Huntington (uno de los miembros de la Comisión Trilateral), escribió: "Poca democracia asegura la gobernabilidad; mucha, la inestabiliza" (Salazar 1998: 300).

Recibido: 10 agosto 2015

Aceptado: 6 octubre 2015

\section{Bibliografía}

Áffonso, Almino; Gómez, Sergio; Klein, Emilio; Ramírez, Pablo (1970), Movimiento campesino chileno. Tomo 1. ICIRA, Santiago.

Alfaro, María (2011), "La Construcción del Movimiento Campesino a partir de las tomas de fundos entre 1971 y 1972", Informe final de Seminario de Grado para optar a Licenciado en Historia, Universidad de Chile.

Ancán, José (2012), Venancio Coñoepan. Editorial USACH, Santiago.

Avendaño, Octavio (2014), "Los partidos frente a la cuestión agraria en Chile, 1967-1973", en Revista de Ciencia Política $\mathrm{n}^{\circ}$ 52, pp. 93-122.

Baland, Jean-Marie; Robinson, James A. (2004), "Land and Power: Theory and Evidence from Chile", en American Economic Review n ${ }^{\circ}$ 98, pp. 1737-1765.

Barraclough, Solon y Fernández, José (1974), Diagnóstico de la reforma agraria chilena. Siglo XXI Editores, México.

Aylwin, Mariana et. al. (1984), Chile en el siglo XX. Editorial Emisión, Santiago, Chile.

Bengoa, José (1983), "El campesinado chileno después de la Reforma Agraria". Ediciones Sur Santiago, Chile.

Bengoa, José (1985), Historia del pueblo mapuche (Siglos XIX y XX). Editorial Sur, Santiago, Chile.

(2002), Historia de un conflicto. El Estado y los mapuches en el siglo XX. Editorial Planeta, Santiago, Chile.

Braudel, Fernand (1970), La Historia y las Ciencias Sociales. Editorial Alianza, Madrid.

Caniuqueo, Sergio (2006), "Siglo XX en Gulumapu: de la fragmentación del Wallmapu a la unidad nacional mapuche. 1880-1978", en Mariman P. et al, i...Escucha, winka...! Cuatro ensayos de Historia Nacional Mapuche y un epílogo sobre el futuro. Lom, Santiago, Chile, pp. 129-217.

Carvajal, Andrés y Peralta, José (2006), A Desalambrar. Historias de mapuches y chilenos en la lucha por la tierra. Editorial Ayun, Santiago, Chile.

Cayuqueo, Pedro (2008), "Rosendo Huenumán. El último parlamentario mapuche", en Punto Final, edición $\mathrm{N}^{\mathrm{o}}$ 667, 25 de julio, versión digital http://www.puntofinal.cl/667/rosendo.php.

Comisión Verdad Histórica y Nuevo Trato (2003a), Historia de los pueblos indígenas de chile y su relación con el Estado, el Pueblo Mapuche. Volumen I, Primera Parte.

(2003b), Propuestas y recomendaciones para un nuevo trato entre el Estado, los pueblos indígenas y la sociedad chilena, Volumen I, Segunda Parte.

\footnotetext{
${ }^{34}$ Ver más detalladamente sobre esta discusión teórica en Órdenes 2014: 25-30.
} 
Comité Interamericano de Desarrollo Agrícola (1966), Tenencia de la Tierra y Desarrollo SocioEconómico del Sector Agrícola. Santiago, Chile.

Correa, Martín y Mella, Eduardo (2009), El territorio mapuche de Malleco: Las razones del illkun/enojo. Memoria, despojo y criminalización en el territorio mapuche de Malleco, Lom Ediciones y Observatorio de Derechos de los Pueblos Indígenas, Santiago, Chile.

Correa, Martín; Molina, Raúl y Yáñez, Nancy (2005), La Reforma Agraria y las tierras mapuches. Chile 1962-1975. Lom, Santiago, Chile.

Crozier J., Michael; Huntington, Samuel P. y Watanuki, Joji (1975). The Crisis of Democracy. Report on the Governability of Democracies to The Trilateral Commission. University Press, New York.

Dahl, Robert (1996) [1971], La Poliarquía. Participación y oposición. Editorial Tecnos, México.

Drake, Paul (1978), Socialism and Populism in Chile, 1932-1952. University of Illinois Press, Urbana.

Dirección General de Estadísticas (marzo, 1931), Resultados del X Censo de la Población, 1930. Volumen I. Imprenta Universo, Santiago, Chile.

Dirección de Estadística y Censos (noviembre, 1960), Censos de Población 1960. Resumen País. Dirección de Estadística y Censos, Santiago, Chile.

Foerster, Rolf y Montecino Sonia (1988), Organizaciones, líderes y contiendas mapuches (19001970). CEM, Santiago, Chile.

Gamboa, Ricardo (2011), "Reformando reglas electorales: La cédula única y los pactos electorales en Chile (1958-1962)", en Revista de Ciencia Política n 31, pp. 159-186.

Garcés, Mario (2004), "Los movimientos sociales populares y la izquierda chilena en la Unidad Popular y su respuesta frente al golpe de Estado de septiembre de 1973", en Centro de Estudios Migue Henríquez, versión digital www.archivochile.com/Ideas Autores/garcesm/garcesm0004.pdf.

Garretón, Manuel Antonio, et. al. (2004), América Latina en el siglo XXI: Hacia una nueva matriz. sociopolítica. Lom, Santiago.

Gazmuri, Cristián (2000), Eduardo Frei Montalva y su época, Tomo I. Aguilar, Santiago, Chile.

Goicovic, Igor (2000), "Del control social a la política social. La conflictiva relación entre los jóvenes populares y el Estado en la historia de Chile", en Última Década Nº12, CIDPA Viña Del Mar, marzo, pp. 103-123.

(2010), "Transición y violencia política en Chile (1988-1994)", en Ayer, № 79. Arce, Madrid, pp. 59-86.

Gómez Leyton, Juan C. (noviembre, 2003) ““1967’ El Año Clave de la Historia Política Reciente Nacional”, en Gómez Leyton, Juan C. (2010), Política, democracia y ciudadanía en una sociedad neoliberal (Chile: 1990-2010). Editorial ARCIS, Santiago, Chile, pp. 49-58.

(2004), La frontera de la democracia: el derecho de propiedad en Chile, 1925-1973. Lom, Santiago.

Habermas, Jürgen (1999) [1975], Problemas de legitimación en el capitalismo tardío. Cátedra, Madrid.

Harnecker, Marta (2003), "Reflexiones sobre el gobierno de Allende: estudiar el pasado para construir el futuro", CLACSO versión digital www.biblioteca.clacso.edu.ar/clacso/otros/20111026114216/allende.pdf.

Hernández, Isabel (2003), Autonomía o ciudadanía incompleta. El Pueblo Mapuche en Chile y Argentina. CEPAL-Pehuén, Santiago.

Huerta, María (1989), Otro Agro para Chile: La Historia de la Reforma Agraria en el Proceso Social y Político. CISEC-CESOC, Santiago, Chile 
Iglesias, Mónica (2015), "Lo social y lo político en Chile: Itinerario de un desencuentro teórico y práctico", en Revista Izquierdas, número 22, enero. Santiago, Chile, pp. 227-250.

Kallfvkvra, Ignacio (9 de septiembre 2014), "Primera organización política mapuche. La Sociedad Caupolicán Defensora de La Araucanía", en El Ciudadano, página web http://www.elciudadano.cl/2014/09/09/114429/primera-organizacion-politica-mapuche-lasociedad-caupolican-defensora-de-la-araucania/ [visitada el 24 de mayo 2014].

Linfati, Angelo (2003), "Violencia patronal durante el procesos de Reforma Agraria en las comunas de Lumaco, Traiguén y Victoria: los 'comités de retomas' y acciones violentas de grupos opositores a la Unidad Popular (1970-1973)”, en Revista Historia en Movimiento, año II, número II, septiembre, pp. 45-58.

Levil, Rodrigo (2006), "Sociedad Mapuche contemporánea", en Mariman Pablo. et al, (2006), ¡...Escucha, winka...! Cuatro ensayos de Historia Nacional Mapuche y un epilogo sobre el futuro. Lom, Santiago, Chile, pp. 219-252.

Llanos, Claudio (2009), “1971-1972: Sublevación en el campo. Poder Popular por decreto versus Poder Popular por las bases", en Cuadernos de Historia $\mathrm{N}^{\circ} 30$, marzo, pp. 68-88.

Lorenzo, Pedro (2001), Fundamentos teóricos del conflicto social. Editorial Siglo XXI, España.

Loveman, Brian (1971), El campesino chileno le escribe a su excelencia. ICIRA, Santiago. y Lira, Elizabeth (2000), Las ardientes cenizas del olvido: vía chilena a la reconciliación política, 1932-1994. Lom, Santiago.

Mallon, Florencia (2004), La sangre del copihue. La comunidad Mapuche de Nicolás Ailío y el Estado Chileno 1906-2001. Lom, Santiago.

Mariman Pablo. et al, (2006), ; ...Escucha, winka...! Cuatro ensayos de Historia Nacional Mapuche y un epílogo sobre el futuro. Lom, Santiago, Chile.

Mariman, Pablo (2012), "La República y los Mapuche: 1819-1828”, en en Naheulpan, Héctor, et al., Ta iñ fijke xipa rakizuameluwün. Historia colonialismo y resistencia desde el país Mapuche. Ediciones Comunidad de Historia Mapuche, Temuco Chile, pp. 65-90.

Mc Adam, Doug, et. al. (1999), Movimientos sociales: perspectivas comparadas, oportunidades políticas, estructuras de movilización y marcos interpretativos culturales. Istmo, Madrid.

Offe, Claus (1991) [1972], Contradicciones en el Estado de Bienestar. Alianza, Madrid.

Olson, M (1965), The Logic of Collective Action. Cambridge, Estados Unidos.

Órdenes, Mathias (2013), "Pensar el Conflicto: intelectuales mapuche en las primeras décadas del siglo XX", en Canales, Pedro y Rea, Carmen (edit.), Claro de luz. Descolonización e 'Intelectualidades Indigenas' en Abya Yala, siglos XX y XXI, pp. 199-233.

Órdenes, Mathias y Díaz-Diego, José (2015), "Discurso y movimiento gremial terrateniente durante la reforma agraria de Eduardo Frei Montalva en el centro y sur de Chile, 1964-1970", en proceso de publicación Revista de Historia Regional, ISI-ESCOPUS, Brasil, volumen 13, 26 páginas.

(2014), "Movimiento mapuche y gobernabilidad democrática. De la Reforma Agraria al Gobierno de Sebastián Piñera (1967-2014)". Tesis para optar al grado de Doctor en "Estudios Latinoamericanos" mención Ciencias Políticas, Universidad ARCIS, Santiago.

Ortega, Emiliano (1987), Transformaciones agrarias y campesinado. De la participación a la exclusión. CIEPLAN, Santiago.

Pairacan, Fernando (2012), "Sembrando ideología: el Aukiñ Wallmapu Ngulam en la transición de Aylwin (1990-1994)", en SudHistoria, $\mathrm{n}^{\mathrm{o}}$ 4, enero-junio, versión digital http://www.sudhistoria.cl/wp-content/uploads/2012/09/Fernando-Pairican.pdf

Peralta, José (2006), "José Peralta", en Carvajal, Andrés y Peralta, José, A Desalambrar. Historias de mapuches y chilenos en la lucha por la tierra. Editorial Ayun, Santiago, Chile, pp. 68-88.

Pichinao, Jimena (2012), "Los parlamentos hispano-Mapuche como escenario de negociación simbólico-político durante la colonia, en Naheulpan, Héctor, et al., Ta iñ fijke xipa 
rakizuameluwün. Historia colonialismo y resistencia desde el país Mapuche. Ediciones Comunidad de Historia Mapuche, Temuco Chile, pp. 25-44.

Pinto, Jorge (2002) La formación del Estado y la nación, y el pueblo mapuche. De la inclusión a la exclusión. Centro de Investigaciones Diego Barros Arana, Santiago, Chile.

Ruíz, Carlos (2005), "El Pueblo Mapuche y el Gobierno de Salvador Allende y la Unidad Popular", en Centro de Estudios Migue Henríquez, versión digital http://www.archivochile.com/Pueblos_originarios/hist_doc_gen/POdocgen0005.pdf.

Saavedra, Alejandro (2002), Los mapuche en la sociedad chilena actual. Lom, Santiago, Chile.

Salazar, Gabriel (1998), "Voluntad política de matar, voluntad social de recordar (a propósito de Santa María de Iquique)", en Artaza, Pablo, et. al., A 90 años de la Escuela Santa María de Iquique. DIBAM, Lom, Centro de Investigaciones Barros Arana, Universidad Arturo Prat, Santiago, Chile, pp. 291-302.

Salazar, Gabriel (2012), Movimientos Sociales en Chile. Trayectoria histórica y proyección política. Uqbar Ediciones, Santiago Chile.

Santana, Roberto (2006), Agricultura chilena en el siglo XX: contextos, actores y espacios agrícolas. CEDER-Centro de Investigaciones Diego Barros, Santiago.

Samaniego, Augusto y Ruiz, Carlos (2007), Mentalidades y políticas Wingka: pueblo mapuche entre golpe y golpe. Editorial CIES, Santiago, Chile.

Tarrow, Sidney (2004), El poder en movimiento. Los movimientos sociales, la acción colectiva y la política. Alianza Editorial, Madrid.

Tilly, Charles (1978), From Mobilization to Revolution. Reading, Estados Unidos.

Tilly, Charles (1995), Las revoluciones europeas 1492-1992. Barcelona.

Tinsman, Heidi (2009), La tierra para el que la trabaja: género, sexualidad y movimientos campesinos en la reforma agraria chilena. LOM Santiago.

Toledo, Víctor (2006), Pueblo Mapuche: derechos colectivos y territorio. Desafíos para la sustentabilidad democrática. Programa Chile Sustentable.

(2007), "La memoria de las tierras antiguas tocando a las puertas del derecho. Políticas de la memoria mapuche en la transición chilena", en Revista de Historia Social y de las Mentalidades, Año XI, Volumen 1, USACH, Santiago.

Tricot, Tito (2013), Autonomía. El Movimiento Mapuche de Resistencia. CEIBO, Santiago, Chile.

Uliánova, Olga (2003), "Levantamiento campesino de Lonquimay y la Internacional Comunista", Estudios Públicos n ${ }^{\circ}$ 89, pp. 173-223.

Unidad Popular (1970), "Programa de Gobierno", versión digital http://www.salvadorallende.cl/Unidad_Popular/Programa\%20de\%20la\%20UP.pdf.

Wolfe, Alan (1980) [1977], Los límites de la legitimidad. Las contradicciones políticas del capitalismo contemporáneo. Siglo XXI, México.

Zabala, José M. (2008), Los Mapuches del siglo XVIII: dinámica interétnica y estrategias de resistencia. Ediciones Universidad Bolivariana, Santiago, Chile.

\section{Prensa}

El Diario Austral.

El Siglo.

Revista Ercilla. 